\title{
Ambiguous Quality Changes from Taxes and Legal Rules
}

\author{
Henry E. Smith†
}

\begin{abstract}
Legal rules have long been analogized to taxes. Conventional analysis has often assumed that the mix of attributes within commodities is either fixed or costlessly measured. This Article explores the consequences for legal rules from dropping this neoclassical assumption of constant quality. Instead, attributes are costly to measure, and substitution can occur by altering levels of attributes (such as durability) within commodities, services, and activities. The Article extends models of quality under commodity-excise taxes to the more complex case of legal rules mandating product enhancements (such as nondisclaimable warranties) and to rules aimed at pricing external harms (such as pollution taxes). The Article shows that the range of possible quality effects, direct and indirect, of legal rules is greater than that in the case of excise taxation and that quality changes present issues of measurement cost that have been overlooked. In particular, these quality responses provide alternative and very different explanations for key data invoked by proponents of behavioral law and economics and by advocates of liability rules over property rules. The possibility of quality changes highlights difficult measurement issues in evaluating the efficiency and equity of legal rules.
\end{abstract}

\section{INTRODUCTION}

Economists and lawyers have long regarded legal rules through the lens of taxation. To do so usually involves adopting a neoclassical framework based on perfect competition in a market in which rational actors buy and sell quantities of homogenous, well defined goods. For those working in transaction-cost economics, of which law and economics is an offshoot, these assumptions can sometimes prove awkward for several reasons. First, as is now well known, the analogy to taxation is itself a bit misleading. For example, legal rules mandating product features may make products more attractive, even if buyers would not have voluntarily paid full cost; taxes generally do not make products more appealing. Originally, it was common to analogize legal mandates to taxes, and to conclude that, as in the case of a tax, buyers were better off to the extent that sellers were unable to "pass on" the costs of the rule. More recently, it has been recognized that buyers are usually better off when the costs can be "passed on" because the higher resulting price may reflect the higher valuation buyers place on

$\dagger$ Associate Professor, Northwestern University School of Law. I would like to thank Ian Ayres, David Haddock, Tom Merrill, Carol Rose, Chris Sanchirico, participants at workshops at the Georgetown and the University of Virginia Law Schools and the Harvard Seminar on Current Research in Taxation, and especially Jeff Strnad for their helpful comments. All errors are mine. This work was supported by a John M. Olin Faculty Fellowship and by the David S. Rudor Corporate Research Fund at the Northwestern University School of Law. 
the product enhanced by the mandated attribute. ${ }^{1}$ For example, a product with a mandated (nondisclaimable) warranty may be more valued by the marginal buyer than was the pre-mandate product without the warranty. ${ }^{2}$ Under certain circumstances of market failure, this theoretically can lead the price increase of the new package to exceed the costs of the warranty (or other mandate).

More fundamentally, the assumptions of neoclassical economics do not translate well into the transaction-cost framework in the first place. The neoclassical world assumes zero transaction costs as part of perfect competition, but the point of transaction-cost economics is to focus on the explanatory role of positive transaction costs. In law and economics, the solution to this problem has usually been to relax some of the assumptions of the neoclassical model of perfect competition pragmatically for the purpose of analyzing legal rules. But others have suggested a more radical abandonment of neoclassical assumptions. Most prominently, behavioral law and economics, drawing on the emerging framework of behavioral economics, drops the traditional assumptions of rationality. ${ }^{3}$ Thus, in the example of mandated warranties, buyers' lack of information or the framing effects emphasized in

1 See Richard Craswell, Passing on the Costs of Legal Rules: Efficiency and Distribution in Buyer-Seller Relationships, 43 Stan L Rev 361, 362,368-85 (1991) (arguing that the intuition that "buyers are more likely to benefit from a rule if sellers are unable to pass along much of their costs" is false).

2 For example, the Magnuson-Moss Warranty-Federal Trade Commission Improvement Act, Pub L No 93-637, 88 Stat 2183 (1975), codified as amended at 15 USC \$§ 2301-12 (1994), provides for nondisclaimable warranties in certain consumer transactions, and these provisions preempt state laws providing less protection, $\$ 2311$ (c). Also, some states have rendered the UCC's implied warranties nondisclaimable in consumer transactions. See UCC § 2-314 (establishing an implied warranty of merchantability); Jean Braucher, An Informal Resolution Model of Consumer Product Warranty Law, 1985 Wis L Rev 1405, 1411 n 25 (noting that five states and New York City prohibit disclaiming implied warranties). Many states' "lemon laws" mandate nondisclaimable warranties. See Yvonne W. Rosmarin and Jonathan Sheldon, Sales of Goods and Services app I (National Consumer Law Center 2d ed 1989) (table of lemon laws). In many jurisdictions, all residential leases contain a nondisclaimable implied warranty of habitability. See, for example, Javins v First National Realty Corp, 428 F2d 1071, 1080, 1082 n 58 (DC Cir 1970) (stating that all housing leases covered by the Washington, D.C., housing code contain an implied warranty of habitability that cannot be waived); Fair v Negley, 257 Pa Super 50, 55-56, 390 A2d 240,242 (1978) (holding that the warranty of habitability implied under Pennsylvania law may not be waived); Anthony T. Kronman, Paternalism and the Law of Contracts, 92 Yale L J 763, 766, 766-86 (1983) ("In many jurisdictions, a nondisclaimable warranty of habitability is now implied, as a matter of law, in every lease of residential property."); Myron Moskovitz, The Implied Warranty of Habitability: A New Doctrine Raising New Issues, 62 Cal L Rev 1444 (1974) (discussing California's adopting an implied warranty of habitability).

3 See, for example, Christine Jolls, Cass R. Sunstein, and Richard Thaler, A Behavioral Approach to Law and Economics, 50 Stan L Rev 1471, 1473-74 \& n 3 (1998) (citing literature); Cass R. Sunstein, Behavioral Analysis of Law, 64 U Chi L Rev 1175, 1175-79 (1997) (arguing that rational choice models, while useful, fail to take into account cognitive errors, motivational distortions, social situations, and other factors that influence people's decisions); Symposium, The Legal Implications of Psychology: Human Behavior, Behavioral Economics, and the Law, 51 Vand L Rev 1495 (1998). 
behavioral law and economics might cause consumers to value the mandated warranty by more than its cost. On this view, the absence of the warranty in the pre-mandate market does not necessarily mean that mandating the warranty is bad for consumers; in behavioral law and economics consumers are not assumed to protect themselves through rational choice.

In this Article, I will argue that analogizing legal rules to taxes provides additional insights, but only after we drop a different neoclassical assumption that is quite common in the literature on legal rules and not uncommon in the tax literature: that commodities and transactions are homogeneous and vary only by price and quantity, that is, that quality is fixed. Instead, I will assume crucially not only that commodities and services are bundles of attributes that can vary from specimen to specimen, but also that measurement of such attributes is costly. Although more recent consumer theory does regard commodities as bundles of attributes, ${ }^{5}$ the measurement-cost framework emphasizes the need to consume resources in measuring these attributes; parties to a transaction must determine the attributes of the product or service they are buying and selling, and such a determination is costly. Thus, the organization of transactions can be seen in large part as solving the consequent problem of minimizing the sum of measurement costs and the losses from leaving attributes unmeasured (and unpriced). Because measurement costs are positive, not all attribute levels that constitute a product's quality will be priced, and, in parallel fashion, when legal rules are imposed, not all such attributes and margins will be specified in the legal rule. Consequently, transactions are subject to adjustment along many margins.

In the tax context, increasing evidence confirms Yoram Barzel's theory that the effect of an excise tax will depend on the interaction of the type of tax and the (endogenous) quality of the taxed item. ${ }^{6}$ Per-

4 These are the basic assumptions of the measurement-cost branch of transaction-cost economics. See, for example, Yoram Barzel, Measurement Cost and the Organization of Markets, $25 \mathrm{~J} \mathrm{~L} \&$ Econ 27 (1982) (stating that measurement of some attributes of goods is costly and may result in errors and that markets have developed arrangements such as warranties, share contracts, and vertical integration to address this problem); Roy Kenney and Benjamin Klein, The Economics of Block Booking, 26 J L \& Econ 497 (1983) (arguing that bundling products with varying qualities can address the measurement cost problem).

5 See, for example, Jack Hirshleifer, Price Theory and Applications 155-56 (Prentice-Hall 3d ed 1984) (" $[\mathrm{A}]$ market commodity is ... desired ... only insofar as it is capable of yielding satisfaction through its attributes."); Kelvin J. Lancaster, A New Approach to Consumer Theory, $74 \mathrm{~J}$ Pol Econ 132 (1966) (arguing that consumers derive utility from the properties or characteristics of goods rather than the goods directly); Sherwin Rosen, Hedonic Prices and Implicit Markets: Product Differentiation in Pure Competition, 82 J Pol Econ 34, 34 (1974) (outlining "a model of product differentiation based on the hedonic hypothesis that goods are valued for their utility-bearing attributes or characteristics"); George J. Stigler and Gary S. Becker, De Gustibus Non Est Disputandum, 67 Am Econ Rev 76,76-77 (1977).

6 See, for example, Yoram Barzel, An Alternative Approach to the Analysis of Taxation, 84 
unit taxes that define the product taxed by reference to a proper subset of its attributes-as is usual-may lead to an increase in the untaxed attributes. Thus, to take the most well studied example, a perpack tax on cigarettes can lead to higher quality cigarettes in terms of taste or length. By contrast, a specific commodity excise tax imposed on an ad valorem (percentage-of-value) basis is usually expected to lead to quality decreases: if attributes can be enjoyed outside the taxed package and if the loss from the separation is outweighed by the tax saved thereby, then the attribute will be severed. The (rump) product will correspondingly show a quality decrease, and under certain circumstances this can even lead the price of the "commodity" after the imposition of the tax to be lower than the pre-tax equilibrium price of the "commodity." For example, an ad valorem tax on "cars" but not on compact disc players could lead to cars being sold without compact disc players (and to induce some buyers who like listening to music while driving to buy and install the compact disc player separately). Under these circumstances, the price rise due to the tax will be mitigated by the price drop from the tax-induced lowering of car quality. In some cases, the post-tax price will appear to be lower than that of the pre-tax equilibrium.

In the following, I will build on the tax literature to provide a new general framework of which taxes and legal rules fall out as subcases. To do so, I will extend Barzel's model of excise taxes to include the types of costs and benefits a legal mandate can present. Within this framework, I will argue that endogenizing "quality" leads to a very different view of the effects of legal rules than is conventionally thought and will allow us additional understanding of how legal rules and taxes are similar and different. I will show that relaxing the neoclassical assumption of homogenous commodities and giving measurement costs a more central place in the analysis of legal rules pro-

J Pol Econ 1177 (1976) (arguing that imposition of a tax leads to adjustments in the attributes of a good in order to achieve tax avoidance); Cecil E. Bohanon and T. Norman Van Cott, Product Quality and Taxation: A Reconciliation, 19 Pub Fin Q 233 (1991) (arguing that in the usual case, specific taxes increase product quality and ad valorem taxes decrease product quality); John Kay and Michael Keen, Product Quality under Specific and Ad Valorem Taxation, 19 Pub Fin Q 238, 239 (1991) (arguing that "the effect of tax structure on product quality is determined by the price elasticity of the consumer's marginal valuation of quality"); Keith B. Leffler, Ambiguous Changes in Product Quality, 72 Am Econ Rev 956 (1982) (concluding that the effect on quality of imposing an excise tax is ambiguous). The apparent disagreements between some of these authors stem from the differing assumptions made about demand in their models. Generally, the conflicting implications of some of these assumptions, noted in passing, support the main argument here: that variable quality makes the effects of legal rules quite difficult to predict and that variable quality causes evidence about legal rules to be ambiguous.

7 Barzel, $84 \mathrm{~J}$ Pol Econ at 1193-95 \& n 30 (cited in note 6); Russell S. Sobel and Thomas A. Garrett, Taxation and Product Quality: New Evidence from Generic Cigarettes, 105 J Pol Econ 880 (1997) (finding fault with previous cigarette studies that conflicted with Barzel's theory and presenting evidence on generic cigarettes consistent with his theory). See also Part III. 
vides a range of insights and an alternative explanation to those provided in the behavioral law and economics and liability-rule literatures. Indeed, the issues I identify and the predictions this framework makes do not even arise in conventional law and economics or even behavioral law and economics, based as they are on the assumption of constant quality.

Quality issues can arise in several legal contexts that might be thought to work differently. In this Article, I will focus on two contexts that exemplify the two major classes of tax-like legal rules: mandated features of buyer-seller contracts and the legal control of externalities such as pollution. In both contexts, I will show that potential quality changes are of two types, what I call "direct" and "indirect." Direct quality changes are those envisioned by officials that make the achievement of the rule's objectives less costly. In the case of mandated product features, the mandated enhancement, say a warranty, can give sellers an incentive to make products safer in order to reduce the cost of the warranty. In the context of an externality such as pollution, abatement measures that firms take in response to an environmental tax allow the achievement of pollution reduction at lower cost than by a simple contraction of output.

These unsurprising but desirable direct quality changes will be contrasted with what I call "indirect" quality changes: quality may change purely to lessen the incidence of the tax-like aspect of the legal rule on the private actors and in a way that does not advance the rule's purpose. For example, to the extent that consumers do not value a mandated warranty, the excess of the cost over this valuation can, like a tax, induce quality changes designed purely to lessen the incidence of this tax-like cost component.

In particular, several broad generalizations about indirect quality changes will emerge. First, once quality is endogenized, we can expect that, with adjustable quality, the deadweight loss from a legal rule is likely to be smaller on the one hand, but the "benefits" aimed for are also likely to be smaller than would be the case with "rigid" quality. Moreover, the effects of legal rules on price and quantity are more difficult to predict, and the data are more ambiguous where quality is variable and costly to measure rather than fixed.

Finally, the range of possible effects on quality from legal rules is greater than that from taxes and makes problems of data and measurement more difficult. In buyer-seller cases in which more than the cost of a legal rule has been "passed on"-cases that are sometimes taken as evidence of a rule's efficiency ${ }^{8}$-we have little assurance that

8 Compare Timothy Besley and Harvey S. Rosen, Sales Taxes and Prices: An Empirical Analysis, 52 Natl Tax J 157, 165-67 (1999) (finding some taxes to increase prices more than 100 
the rule actually is efficient or benefits consumers, because the price rise may reflect a change in quality of the underlying "product" rather than an increased willingness to pay for a simple sum of the premandate product plus the legally mandated feature. The post-mandate data will not necessarily reflect the same underlying product as was observed in the market equilibrium before the imposition of the mandate. Separating out the price effects stemming from the value to consumers of the warranty or other legal rule from those attributable to indirect changes in product or transaction "quality" will pose very difficult econometric puzzles. Further, the impact on different consumers of these quality changes may differ, leading to undesirable effects from the standpoint of fairness.

In the other major context, that of taxes and liability rules aimed at internalizing externalities, direct quality effects are fairly uncontroversial. Private actors who face liability will make their own internal cost-benefit analyses which may result in altering quality-say adding pollution abatement equipment to a production process-that makes the achievement of the legal regime's goal of a cleaner environment less costly. The cheapest-cost-avoider analysis draws strength from the ability of liability rules to harness private information about costs.

But where harm is costly to measure, I will argue that indirect quality effects can weaken the increasingly popular case for liability rules over property rules based on their apparently lesser informational requirements. What I call the "informational-subset" argument has taken the information-harnessing effect of liability rules even further by claiming that liability rules are generally superior to property rules because they only require analysis of external harms, whereas property rules and direct regulation require officials to assess and weigh both benefits and the costs of achieving them. ${ }^{9}$ But indirect quality changes can alter this supposed subset relationship. If actors can easily alter the mix of attributes in their products or activities toward attributes that are difficult to measure, the informational-subset argument no longer holds. In the pollution context, when polluters can, for example, alter the mix of pollution toward harmful but harderto-measure components, some form of quantity regulation can be superior to the pricing mechanism so favored among a growing number of commentators.

percent of the amount of the tax and advancing hypothesis of imperfect competition within a rigid-quality framework); Craswell, 43 Stan L Rev at 361 (cited in note 1); Jolls, Sunstein, and Thaler, 50 Stan L Rev at 1505-08 (cited in note 3).

9 This argument has been made in its strongest form yet in Louis Kaplow and Steven Shavell, Property Rules Versus Liability Rules: An Economic Analysis, 109 Harv L Rev 713 (1996). For additional citations and discussion, see Part III. 
What we think of as a "product" or an "activity" is itself a function of measurement costs. Much of the following will be concerned with substitutions against the tax-like component of legal rules. But unlike substitutions between one product or activity and another, altering the levels of the various attributes of a product or an activity is likely to be less visible because they are more costly to measure. It is simply easier to measure numbers of toasters or volume of output rather than the many attributes (wiring, chemical make-up, etc.) that comprise them. As will emerge, theoretical analysis and empirical studies conventionally proceed on the basis of a very simplified notion of quality. But where the legal system itself may be imposing costs on the quality attributes, there is little reason other than ease of measurement to ignore quality. How markets, officials, and economists carve up the world into products and activities is all a function of costly measurement.

In general, a framework based on endogenous quality highlights the likelihood that information costs for devising an effective legal mandate will be high, particularly where measurement costs lead "unregulated" parties themselves to leave attributes and margins unpriced. Measurement costs and the possibility of quality changes that reflect them require more systematic attention. Part I supplies a framework for analyzing direct and indirect quality changes induced by taxes and legal rules. This framework is then applied in Part II to mandated product improvements in buyer-seller contracts and in Part III to rules like Pigovian taxes, liability rules, and subsidies that "price" externalities. In Part IV, I show how indirect quality changes can cause systematic ambiguities in the very data that would be used ex post to evaluate the success of legal rules. Part $V$ draws out the implications of measurement costs and variable quality for the design of legal rules in terms of efficiency and equity.

\section{A FRAMEWORK FOR QUALITY CHANGES FROM TAXES AND LEGAL RULES}

This Article will explore the changes in quality that can be induced by taxes or legal rules. These quality effects will allow a more complete picture of the analogy from legal rules to taxes. ${ }^{10}$ Although traditional commentary tends to analogize legal rules to taxes, the

10 In this Article, I will follow the usual practice in law and economics of using partial equilibrium analysis; that is, I assume that prices outside the market I am considering are constant. Although partial equilibrium analysis can be problematic, it can be an appropriate first approximation. More importantly, the theme of this Article - that quality changes lead to ambiguities-is if anything reinforced by the possibility of feedback effects in a general equilibrium framework. On partial versus general equilibrium analysis, see, for example, Andreu Mas-Colell, Michael D. Whinston, and Jerry R. Green, Microeconomic Theory 341-43, 538-40 (Oxford 1995). 
analogy is more straightforward for some rules than for others. Indeed liability rules, such as strict liability in tort, are straightforwardly viewed as Pigovian taxes ${ }^{11}$ with the proceeds going to the victims of the externality. Less directly, laws that mandate product features in buyer-seller relationships can be analogized to taxes. Previous analyses of taxes and legal mandates assume constant quality, which makes the taxes and mandates look deceptively dissimilar. As I will show, the range of possible effects on quality from legal rules is potentially greater than in the case of revenue-raising commodity taxes, and, interestingly, the potential for these effects leads to ambiguities in the data used to evaluate such rules.

After setting out traditional approaches to the passing on of the costs of taxes and legal rules, I present my framework for exploring the implications of variable quality on these issues. At the end of this Part, I begin to apply these tools to the seemingly more familiar case of Pigovian taxes and liability rules and find that, here too, endogenizing quality leads to the unexpected result that property rules can be superior to liability rules more often than is recognized from within the neoclassical, constant-quality framework.

\section{A. Previous Approaches to Passing on Costs}

A long tradition analogizes the imposition of a mandate on a buyer-seller relationship to the imposition of an excise tax on the sale. This deceptively attractive analogy masks important differences between taxes and legal rules, differences that are receiving increasing attention in the traditional constant-quality framework. ${ }^{12}$ In essence, the analogy between taxes and legal rules often overlooks the increased willingness of the marginal consumer to pay for the product or the service that has been enhanced by the mandated feature. Even though possible shifts in demand do complicate the relationship between taxes and legal rules, I will later argue that the analogy becomes useful once we consider quality changes.

According to the original analogy that ignores shifts in demand, a legal rule will merely make the commodity or service in question more costly. This "cost" is then treated just as would a tax or input factor price increase, as illustrated in Figures $1 \mathrm{~A}$ and $1 \mathrm{~B}^{13}$

11 Pigovian taxes are charges for units of an activity that are intended to internalize external costs and thereby bring actors' decisions closer to social optimality. See the sources cited in note 70. See also, for example, Richard Cornes and Todd Sandler, The theory of externalities, public goods, and club goods 68-69, 72-81 (Cambridge 2d ed 1996).

12 See, for example, Craswell, 43 Stan L Rev 361 (cited in note 1); Lawrence H. Summers, Some Simple Economics of Mandated Benefits, 79 Am Econ Rev (Papers and Proceedings) 177, 179-81 (1989). See also Jolls, Sunstein, and Thaler, 50 Stan L Rev at 1471 (cited in note 3).

13 The "cost" here may initially be different for different sellers. In a competitive market 
FIGURE 1A

EFfECTS OF A COST INCREASE WITH RELATIVELY ELASTIC DEMAND

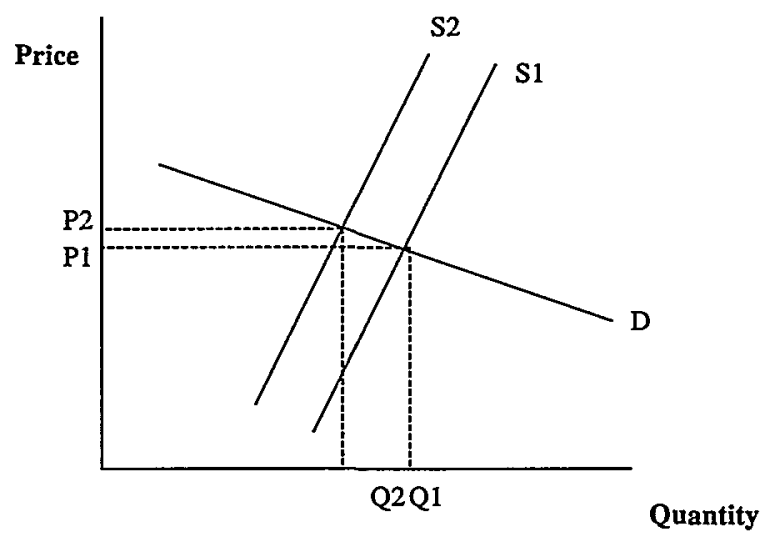

FIGURE $1 B$

EFFects OF a COST INCREASE WITH RELATIVELY ElASTIC SUPPLY

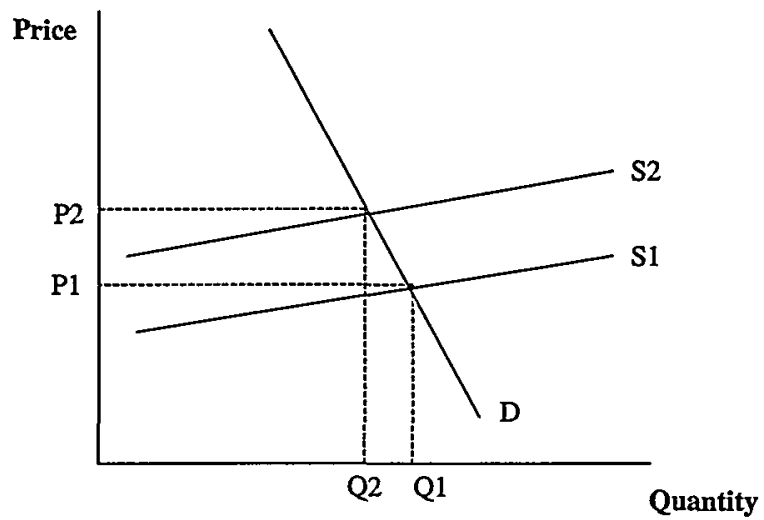


Where supply is relatively inelastic and demand relatively elastic, as in Figure 1A, costs tend not to be passed on to consumers (i.e., P2$P 1$ is small), but quantity falls by a large amount. But where, as in Figure $1 \mathrm{~B}$, supply is relatively elastic and demand inelastic, costs do tend to be passed on (i.e., $P 2-P 1$ is large), but quantity does not fall much. The former, Figure 1A, situation (inelastic supply, elastic demand) tends to result in a large decrease in quantity and a small increase in price, and the latter, Figure 1B, situation (elastic supply, inelastic demand) leads to a small decrease in quantity but a large increase in price. ${ }^{14}$ This is fairly straightforward in the case of a tax, slightly less so for input price increases. For the latter, the "cost" that can be passed on in a competitive market is that of the sellers for whom the contribution of the input price increase to the marginal cost of their product or service is least, after adjustments to production have been made.

In the case of legal rules, this simple view of cost is deceptive, because it is taken to mean that buyers are better off to the extent that price does not rise. Just as a seller can pass on the cost of an excise tax more or less depending on the elasticities of supply and demand, so, it is argued, sellers will be able to "pass on" a portion of the cost of a legal rule depending on relative elasticities. From this it is concluded that buyers are better off just to the extent that costs cannot be passed on. However, unlike a tax or an increase in the price of an input, the legal mandate may make the product more attractive to consumers. ${ }^{15}$ In particular, the more the marginal consumers' valuation of the product increases after the mandate is imposed, the more demand will shift outward, and this can explain a price increase.

Consider Figures 2A and 2B, which illustrate Richard Craswell's analysis of the case of the inefficient and efficient warranty. ${ }^{16}$ For now,

only the costs that the least-cost sellers face would be "passed on." See, for example, Richard Craswell and Alan Schwartz, Foundations of Contract Law 39 (Oxford 1994). The assumption of a competitive market is not essential to all the points that follow, but aids the exposition considerably and allows better comparison to previous work. In the following, I will note where this assumption matters.

14 The terminology of "pass on" is somewhat unfortunate, particularly in the case of legal mandates. Following Craswell, I use "pass on" to mean that the rise in price exceeds the per-unit cost increase. If a seller "passes on" less than 100 percent of his or her costs, this does not mean that sellers suffer a loss or that they earn less than a competitive profit. A seller may have instead reduced his or her per-unit production costs by producing less output. Craswell, $43 \mathrm{Stan} \mathrm{L}$ Rev at $367 \mathrm{n} 11$ (cited in note 1 ).

15 See id at 362,368-72,383-85 (arguing that a mandated warranty causes an upward shift in the demand curve equal to increased willingness to pay, reflecting the amount of consumer benefit); Summers, 79 Am Econ Rev at 179-81 (cited in note 12).

16 See Craswell, 43 Stan L Rev at 368-72 (cited in note 1). 
FIGURE 2A

AN INEFFICIENT WARRANTY

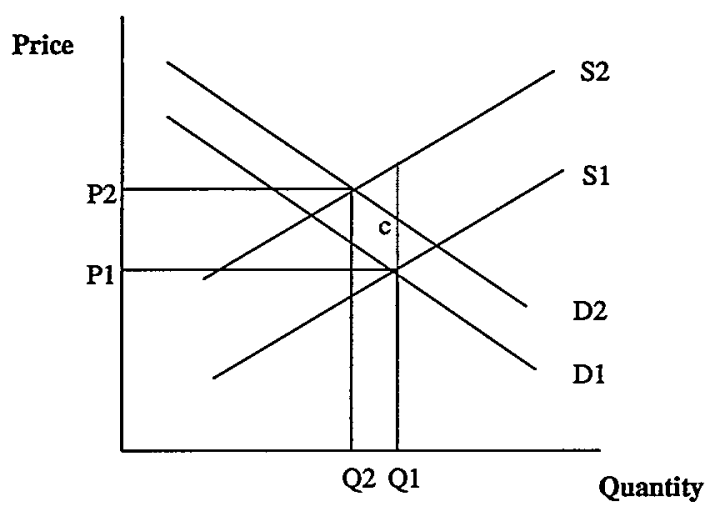

FIGURE 2B

AN EFFICIENT WARRANTY

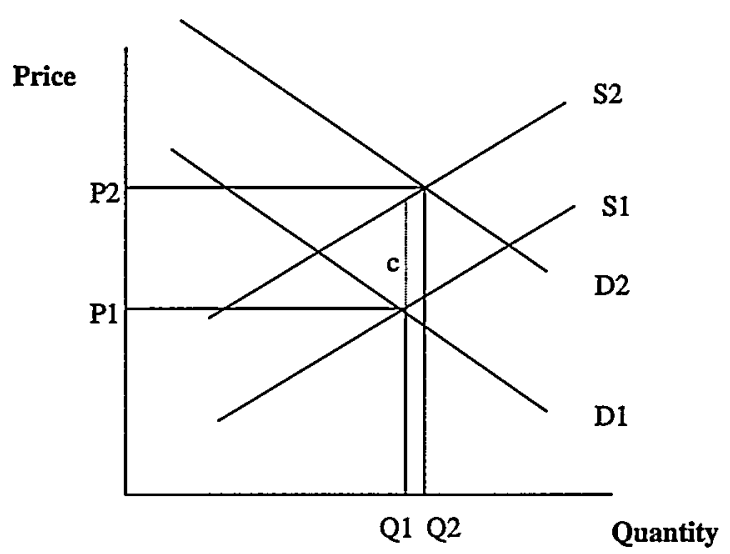


it is assumed that sellers cannot price discriminate and that consumers are homogenous in their valuation of the warranty. ${ }^{17}$

In the case of the inefficient warranty, consumers' willingness to pay increases less than the cost increase due to the warranty; demand rises by less than the cost of the warranty $(D 2-D 1$ is less than $c) .{ }^{18} \mathrm{Im}$ posing the warranty results in a decrease in quantity and in a price increase $(P 2-P 1)$ that is less than $c$ : not all of the cost $(c)$ has been "passed on." By contrast, in the case of the efficient warranty, consumers' increase in willingness to pay exceeds the cost of the warranty; demand rises more than cost (D2-D1 is greater than $c)$. Quantity increases overall, and the price increase $(P 2-P 1)$ exceeds the cost of the warranty $(c)$. It appears that more than 100 percent of the cost of the warranty has been passed on. (If demand increased by the same amount as cost there would be no price increase or shift in quantity, and exactly 100 percent of the warranty's cost would have been passed on.) Thus, greater willingness to pay in the case of the marginal consumer means that more of the cost will appear to have been passed on. And as long as inframarginal consumers ${ }^{19}$ value the warranty by at least as much as the marginal consumers, overall consumer welfare is increased. ${ }^{20}$

For example, a product such as a toaster with a warranty is more attractive than the product without one. The demand for toasters will shift up by the amount that the value to the marginal consumer of the toaster with the warranty exceeds the value to the marginal consumer of the toaster without the warranty. This outward shift in demand will push both quantity and price upward. And, if the marginal consumer values the warranty more than its cost, then the price increase will exceed the cost. But, as Craswell points out, in many cases, this complicates the simple tax analogy because now consumers are better off to the extent that sellers can pass on the costs, as illustrated in Figure $2 \mathrm{~B}^{21}$ The shift outward in demand reflects increased willingness to pay because of the value derived from the warranty. The more demand shifts upward from its pre-warranty value, the more the price rise would be regarded as a sign that at least the marginal consumers are better off. Whether inframarginal consumers are better off will de-

17 This could either arise because all consumers do have the same valuation or because the loss of economies of scale does not prevent sellers from differentiating the package by classes of consumers, resulting in submarkets of homogeneous consumers. Id at $373 \mathbf{n} 19$.

18 The marginal consumer need not be the same set of consumers in each case. In some of the following, I will assume that consumers all have the same valuation. This is of course inappropriate when considering the distributional aspect of legal rules.

19 Inframarginal consumers are those who value the package more than the equilibrium price (which reflects the willingness to pay of the marginal consumer).

20 See Part V.A for further discussion.

21 Craswell, 43 Stan L Rev at 371 (cited in note 1). 
pend in turn on their valuations of the warranty relative to that of the marginal consumers. " Consumers "as a whole" will benefit if aggregate consumer surplus is increased.

The price increase can even exceed the cost of the legal rule, as it does in Figure 2B, and it will if the marginal consumer values the mandated attribute more than cost. Prior to the imposition of the legal rule, consumers might be unaware of or misperceive the benefits of the legal rule. If consumers do not know beforehand that they would indeed value a warranty more than its cost and if a lawmaker knows this, then one would have a paternalistic justification for the mandate. If consumers were aware of the benefit once they started to enjoy it, the price would rise to reflect this increased willingness to pay and the paternalistic justification for the mandate would seem to receive its confirmation.

As Craswell points out, framing effects, to the extent that they exist for items like warranties, would work similarly, and this has become the foundation for more recent work in behavioral law and economics. ${ }^{23}$ Under framing theory, also known as the endowment effect, a consumer would be willing to pay less for the entitlement than she would have to be paid in order to give it up. ${ }^{24}$ In the framing scenario, we have two demand curves, a lower one reflecting willingness to pay and a higher one for willingness to accept. There is no a priori reason

22 Id at 372-85 (explaining that because consumers differ in their willingness to pay for a warranty, some may be made better off by a warranty while others might be made worse off).

23 Id at 387-91 (suggesting that framing effects may make an efficiency analysis indeterminate). It is not clear that a consumer would feel that a legally mandated warranty is an "endowment" if she has not yet bought the product in question. See also Russell Korobkin, The Status Quo Bias and Contract Default Rules, 83 Cornell L Rev 608.611-12.633-47 (1998) (finding endowment effect in default rules in a role-play experimental setting).

24 See Daniel Kahneman and Amos Tversky, Prospect Theory: An Analysis of Decision Under Risk, 47 Econometrica 263 (1979) (discussing basics of the endowment effect); Daniel Kahneman, Jack L. Knetsch, and Richard H. Thaler, Experimental Tests of the Endowment Effect and the Coase Theorem, $98 \mathrm{~J}$ Pol Econ 1325 (1990) (arguing that endowment effects persist even in market settings where the participants have opportunities to learn); Jack L. Knetsch, The Endowment Effect and Evidence of Nonreversible Indifference Curves, 79 Am Econ Rev 1277 (1979) (reporting tests demonstrating the endowment effect); Amos Tversky and Daniel Kahneman, Loss Aversion in Riskless Choice: A Reference-Dependent Model, 106 Q J Econ 1039 (1991) (presenting theoretical explanation for the endowment effect based on loss aversion). For a sympathetic summary of work in this area, see Richard H. Thaler, The Winner's Curse: Paradoxes and Anomalies of Economic Life ch 6 (Princeton 1992). For a recent exchange on the robustness and the scope of the endowment effect, see Jason F. Shogren, et al, Resolving Differences in Willingness to Pay and Willingness to Accept, 84 Am Econ Rev 255 (1994) (finding in contrast to previous studies a convergence between willingness to pay and willingness to accept for market goods with close substitutes but persistence of the divergence for nonmarket goods with imperfect substitutes); Gwendolyn C. Morrison, Resolving Differences in Willingness to Pay and Willingness to Accept: Comment, 87 Am Econ Rev 236 (1997) (arguing that Shogren et al's results are insufficient to reject endowment effect); Jason F. Shogren and Dermot J. Hayes, $R e$ solving Differences in Willingness to Pay and Willingness to Accept: Reply, 87 Am Econ Rev 241 (1997) (defending conclusions of earlier study and describing additional study). 
to favor one over the other in determining whether consumers in the aggregate benefit from a mandate, but to the extent that framing is involved, the price of the product with the warranty can exceed the old price plus the cost of the warranty. ${ }^{25}$

Recently, behavioral law and economics has built on Craswell's analysis in order to illustrate the implications of the endowment effect for the design of legal rules. ${ }^{26}$ The prime empirical example is drawn from employment law. One study is consistent with the interpretation that more than 100 percent of the cost of mandated maternity health coverage is "passed on" to female employees in the form of lower wages. $^{27}$ According to Sunstein, Jolls, and Thaler this can be seen as evidence that workers' willingness to pay and willingness to accept diverge, just as the endowment effect literature would lead us to expect. $^{22}$

This is a possible interpretation, but it, like the literature it builds on, implicitly assumes that the underlying product or service (or employment relation) does not change in quality in response to the cost of the legal rule. I will argue that alternative views of such examples are possible once we allow for quality changes along the many unpriced margins at the control of the transactors. The use of price movements in behavioral law and economics turns out to be a thorny problem, to which I return after presenting a framework for endogenizing quality changes. ${ }^{29}$

\section{B. Direct and Indirect Quality Changes from Taxes and Legal Rules}

Consider the possibility of quality changes along margins unspecified by the legal rule. In the limiting case, a legal rule is not valuable at all to the consumer. This case is not so interesting in itself, but it does allow one to consider some additional effects of quality changes. In the limiting case, these quality changes would be like those explored in the literature on excise taxes and on the closely related

25 The framing effect can lead to indeterminacy in efficiency analysis; the mandate will look better if the outer demand curve reflecting an endowment is used to measure consumer demand. See Craswell, 43 Stan L Rev at 387-91 (cited in note 1) (suggesting that consumers may be willing to pay more for a warranty provided by the law than for a warranty not provided by the law and that efficiency analysis is indeterminate if the warranty costs sellers an amount between these two values).

26 Jolls, Sunstein, and Thaler, 50 Stan L Rev at 1505-08 (cited in note 3) (stating that the endowment effect may explain why wages fall by more than the cost of the benefit received in certain cases).

27 Jonathan Gruber, The Incidence of Mandated Maternity Benefits, 84 Am Econ Rev 622, 623 (1994).

28 Jolls, Sunstein, and Thaler, 50 Stan L Rev at 1505-08 (cited in note 3), citing Gruber, 84 Am Econ Rev 622 (cited in note 27).

29 See Parts IV.B and V.B.2. 
Alchian-Allen proposition that fixed transportation charges cause quality increases. ${ }^{30}$ After explaining this limiting case, I will analyze the more realistic case in which the attribute mandated by the legal rule has some nonzero value to the marginal buyer.

Before proceeding, a word on terminology is in order. What we commonly call "tax" laws can often have the effect of mandating features of a transaction or activity. For example, the Internal Revenue Code's provisions on the qualifications for tax-exempt status and for eligibility for deductible charitable contributions have the effect of regulating the form in which charities and some other organizations do business. "In the following, I will use "legal rule" to cover provisions (whether denominated "taxes," "regulations," etc.) that aim to regulate or price behavior. I will show that these rules can be broken up into a commodity-tax-like component and a remainder. Strictly speaking, it is this remainder that distinguishes "legal rules" from taxes.

\section{Taxes under variable quality.}

If we allow quality to vary, even the effects of an excise tax or a transportation fee can lead to increases or decreases in price that are unexpected on the traditional assumption that the quality of the product or service is constant. These effects of variable quality will depend on whether the tax in question is imposed on a per-unit or an ad valorem basis. In either case, it will be assumed that the tax statute does not specify every conceivable attribute of the commodity in question but singles out the most important. ${ }^{32}$

Consider first a per-unit excise tax on one commodity. Take a well known example, a tax imposed on light bulbs in which each unit is taxed a flat amount. ${ }^{33}$ Some attributes like durability are not mentioned in the tax statute. If so, then part of the tax can be avoided if sellers and buyers shift to longer-lasting light bulbs-even if on a perunit-of-service basis the marginal cost of a light bulb is greater. That is, the tax burden is lessened if one buys fewer bulbs that last longer; one can enjoy light services at a lower cost per unit of service. Suppose, for example, that before the tax, light bulbs that last one month cost $\$ 1$ per bulb and those that last two months cost $\$ 2.25$. Then lighting costs

30 See notes 37-38 and accompanying text.

31 See 26 USC \$ 501(c)(3) (1994) (specifying criteria for tax-exempt organizations to be eligible for deductible charitable contributions); 26 USC $\S 501(c)(2),(c)(4)-(c)(19)(1994)$ (specifying criteria for tax-exempt status of the organization itself).

32. This is a realistic assumption. See Barzel, $84 \mathrm{~J}$ Pol Econ at 1178 (cited in note 6) (noting that, although the legal definition of a product or service may expand over time, it is still unlikely to cover all relevant characteristics). See also Part V.

33 Barzel, $84 \mathrm{~J}$ Pol Econ at 1186-90 (cited in note 6). 
$\$ 1$ per month with the short-lived bulbs and $\$ 1.12$ (\$2.25/2) with the latter, and so the former, one-month bulbs will be chosen. ${ }^{34}$ If a tax of $\$ 0.75$ per bulb is now imposed, the one-month bulbs will now cost $\$ 1.75$ per month of lighting, and the two-month bulbs will cost $\$ 1.50$ $((\$ 2.25+\$ 0.75) / 2)$ per month. With the tax, the two-month bulbs are now cheaper to consumers and will be chosen, even though they are more expensive to produce. Higher quality (here longer-lasting) light bulbs will be substituted for the original light bulbs. Similarly, for light bulbs that are typically used in pairs, single brighter (higher-quality) bulbs might be substituted in order to evade the tax.

More generally, in a competitive market, assuming that buyers know the quality attribute, the transactors are expected to minimize the sum of the deadweight loss and the tax paid. ${ }^{35}$ However, the deadweight loss in such cases comprises not only the familiar (but now smaller) welfare-loss triangle but also a component representing the extra production costs for the higher quality bulbs. This can be illustrated graphically as in Figure 3.

34 I am ignoring the age-old question of how many people it takes to change a light bulb (and what their cost of doing so is). Alternatively the prices cited in the text can be considered to include these costs.

35 In a perfectly competitive market, consumers costlessly measure attributes. In other competitive markets, adjustment will occur to the extent that consumers value the attribute and can cost-effectively be assured of getting what they pay for. Monopoly or oligopoly power can add further complications that can also be relevant to the issue of quality. See, for example, Drew Fudenberg and Jean Tirole, Game Theory 401-05 (1991) (discussing bargaining over an object with unknown value in a bilateral monopoly situation); David Besanko, Shabtai Donnenfeld, and Lawrence J. White, Monopoly and Quality Distortion: Effects and Remedies, 102 Q J Econ 743 (1987) (discussing possible remedies for monopolist-induced quality distortions); R.H. Coase, Durability and Monopoly, $15 \mathrm{~J}$ L \& Econ 143 (1972); Kai-Uwe Kühn and A. Jorge Padilla, Product line decisions and the Coase conjecture, 27 Rand J Econ 391 (1996); Alan Schwartz, A Reexamination of Nonsubstantive Unconscionability, 63 Va L Rev 1053, 1071-75 (1977) (discussing conditions under which a monopolist is as responsive to consumer preferences in contract terms as a nonmonopolist would be); A. Michael Spence, Monopoly, quality, and regulation, 6 Bell J Econ 417 (1975) (arguing that rate of return regulation best counters non-optimal quality setting by monopolists). In particular, mandates might be strategic complements or substitutes with quality in other markets. See Jeremy I. Bulow, John D. Geanakoplos, and Paul D. Klemperer, Multimarket Oligopoly: Strategic Substitutes and Complements, 93 J Pol Econ 488 (1985) (analyzing how changes in an oligopolist's actions in one market affect other markets). 
FIGURE 3

\section{DURABILITY SHIFT FROM PER UNIT EXCISE TAX}

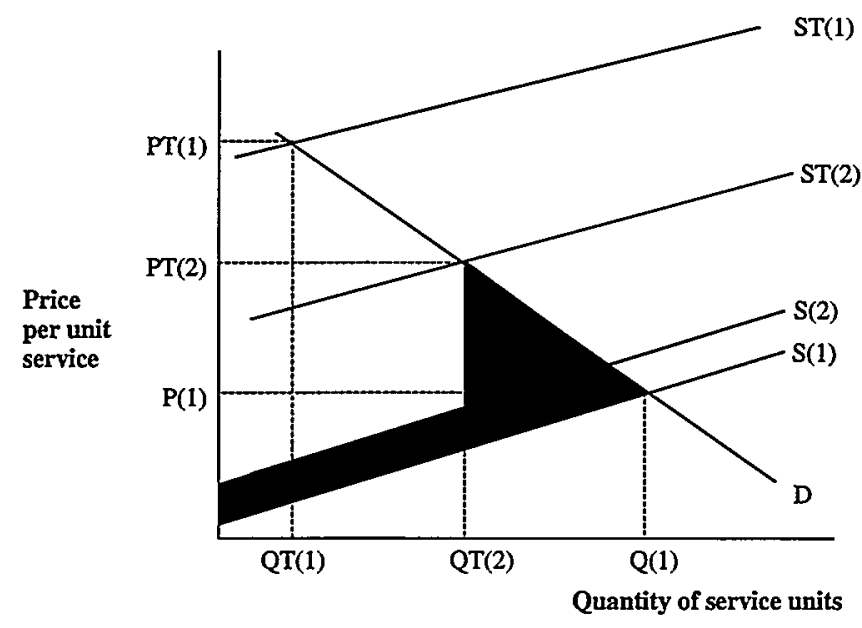

The $S(1)$ curve represents the supply of the low-durability bulb and it is chosen in pre-tax equilibrium over the longer durability bulb, whose supply curve $S(2)$ is higher (more costly). With the imposition of the tax, the low-durability curve shifts up by more (to $S T(1)$ ) than does the high-durability curve (to $S T(2)$ ), because consumers buying low-durability bulbs have to pay the tax more frequently. Since $S T(2)$ is lower than $S T(1)$, higher quality is chosen after the tax, and the quantity of service units falls less-to $Q T(2)$ rather than to $Q T(1)-$ and the price per unit of service rises less-to $P T(2)$ rather than $P T(1)$ - than expected on rigid quality. The welfare-loss triangle (lighter shading) is smaller than it would be with rigid quality, ${ }^{36}$ but there is an extra component of waste corresponding to the increased production costs from evading the tax (darker shading). If transactors were constrained to keep the durability of the light bulbs at the original level, the conventional analysis - with its price, quantity, and welfare-loss triangle-would hold. But, as long as some of the many margins along which transactors can adjust are left unconstrained by the tax statute, then the possibility of adjustment remains.

This adjustment to a per-unit excise tax is reminiscent of the Alchian-Allen proposition. According to this proposition, a transportation charge will lead to a substitution away from lower to higher qual-

36 Under rigid quality, the welfare-loss triangle would be the larger triangle extending from $Q(1)$ leftward all the way to $Q T(1)$, the quantity chosen under the tax and rigid quality. 
ity items. ${ }^{37}$ This leads to the (observed) effect of "shipping the good apples out." If low-quality apples (ones that do not taste as good, etc.) cost $25 \phi$ to produce and high-quality apples cost $50 \phi$ to produce, in the local market one high-quality apple costs the same as two low-quality apples. If shipping the apples across the country costs $25 \not$ per apple, then this relationship is disturbed. Now a low-quality apple costs $50 \phi$ and a high-quality apple costs $75 \phi$. In the distant market a high-quality apple costs the same as only one and one-half low-quality apples. The relative prices have changed and because the high-quality apples are relatively cheaper than they are in the local market, consumers in the distant market will lessen apple consumption, but within apples consumed will substitute into high-quality apples from low-quality apples. ${ }^{33}$ Demand for high-quality apples will be greater relative to the demand for low-quality far away than close by the site of production, and the average price paid for apples in the distant area will exceed the sum of the cost of the average apple sold near the production site and the transportation charge because relatively more high-quality, expensive apples will be sold in the distant market. Just as in the case of the per-unit tax on the producer side, the transportation cost causes an adjustment on the consumer side - a substitution to higher quality.

Some taxes, in contrast, are imposed on an ad valorem basis and their effects with endogenous quality are expected to be very different from those in the case of the per-unit tax. ${ }^{39}$ Once again, in the most interesting case - and the one most parallel to legal rules-the tax statute does not specify all the possible attributes of the commodity and so does not foreclose every avenue of adjustment. If a product-specific

37 See Armen A. Alchian and William R. Allen, University Economics 74-75 (Wadsworth 1964). For general discussions of the Alchian-Allen theorem, see Thomas E. Borcherding and Eugene Silberberg, Shipping the Good Apples Out: The Alchian and Allen Theorem Reconsidered,86 J Pol Econ 131 (1978) (rebutting challenges to the Alchian-Allen theorem); Tyler Cowan and Alexander Tabarrok, Good Grapes and Bad Lobsters: Applying the Alchian and Allen Theorem, 33 Econ Inquiry 253 (1995) (arguing that the Alchian-Allen theorem applies when costs are imposed on a per-unit basis, but not when on a "fixed-fee" basis); John P. Gould and Joel Segall, The Substitution Effects of Transportation Costs, 77 J Pol Econ 130 (1969) (arguing that the Alchian-Allen theorem need not hold when substitution effects are considered); John Umbeck, Shipping the Good Apples Out: Some Ambiguities in the Interpretation of "Fixed Charge", $88 \mathrm{~J}$ Pol Econ 199 (1980) (refuting Gould and Segall and asserting that the Alchian-Allen theorem applies irrespective of substitution effects).

38 As has often been pointed out, even in the absence of income effects, this substitution effect can theoretically be overcome by interaction with a third good. See, for example, Gould and Segall, $77 \mathrm{~J}$ Pol Econ at 132-37 (cited in note 37) (explaining that the introduction of a substitute third good may result in a smaller proportion of the quality good being consumed in the distant market); Borcherding and Silberberg, $86 \mathrm{~J}$ Pol Econ at 136-37 (cited in note 37) (analyzing the possibility of third-good effects and defending the empirical usefulness of Alchian-Allen theorem).

39 See Barzel, $84 \mathrm{~J}$ Pol Econ at 1183-85 (cited in note 6) (arguing that an ad valorem tax leads to a decrease in quality and may even lead to a price below the pre-tax price). 
tax is imposed on an ad valorem basis, attributes are only taxed if they remain part of the package. But if they are dropped from the package, they are not taxed. (This of course does not apply to an ad valorem tax on every commodity in the economy.) Thus, if an ad valorem tax is imposed on cars, it will be difficult to define "car" in such a way that quality adjustment is not possible, because cars have thousands of attributes that consumers are sensitive to, either directly or indirectly. If the tax is ad valorem, transactors will have an incentive to drop attributes from the car as long as the separation is less costly than the tax saved. So we would expect that air conditioners and compact disc players might be dropped from the commodity called "car" and sold separately, so that they do not face the tax. As long as, to the marginal consumer, the pre-tax advantage of including the attribute in the package over selling it separately is less than the tax saved by eliminating the attribute plus the decrease in price of the product resulting from the dropped attribute, such attributes would be dropped. ${ }^{40}$ We expect, if anything, a lowering of quality in response to an ad valorem tax. Again, the quantity of service units should drop by less than it would in the fully constrained case of the conventional analysis, but, unlike with the per-unit tax, this time we expect price to be less than conventionally expected, as illustrated in Figure 4.

FIGURE 4

EFFECTS OF AN AD VALOREM TAX

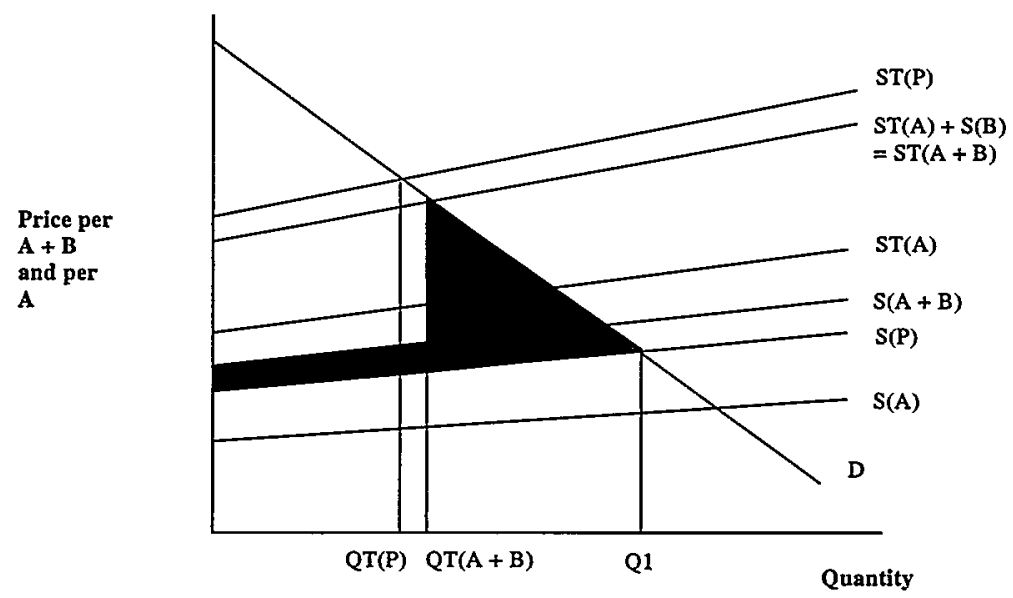

40 Id. Post tax, consumers might purchase the item separately and install it or might shift their consumption elsewhere. 
In Figure 4, lower quality leads to a lower price than expected under rigid quality. Here $S(A)$ represents the supply of $A$ alone, $S(P)$ the supply of the package that contains both $A$ and $B, S(A+B)$ is the supply of $A$ and $B$ separately (the vertical sum of $S(A)$ and $S(B)$ ). Similarly, $S T(A)$ is the (upwardly shifted) supply curve of $A$ alone after the imposition of the tax, $S T(A+B)$ is the supply of $A$ and $B$ separately after the tax, and $S T(P)$ is the supply of the $A$-plus- $B$ package after the tax. The separate supply curve shifts up (to $S T(A+B)$ ) by less than the supply curve for the package (to $S T(P)$ ), causing post-tax equilibrium quantity to fall less with variable quality (from $Q 1$ to $Q T(A+B)$ ) than it would if quality were constrained to the pre-tax equilibrium product with both $A$ and $B$ (from $Q 1$ to $Q T(P)$ ). That is, $Q T(A+B)$ exceeds $Q T(P)$. The price corresponding to the variablequality equilibrium quantity $Q T(A+B)$ is lower here than the price corresponding to the fixed-quality equilibrium quantity $Q T(P)$. In extreme cases, the price can fall below the equilibrium price before the imposition of the tax. This is not possible on the conventional view where the price will, if anything, rise (and would remain the same only in the case where the elasticities dictate that none of the tax can be "passed on" to the buyer). Because the adjustment to the tax is completely analogous to the adjustment to a rise in a factor price, a competitive market can be expected to supply the quality level that minimizes the sum of the tax paid, the welfare loss (triangle) from reduced production, and the loss of efficiency in production. ${ }^{42}$

It is worth stressing that both the quality changes themselves and the fact that they differ for per-unit and ad valorem taxes stem ultimately from the costliness of measuring and specifying margins. In particular, if all attributes could be specified perfectly in the definition used in the legal rule, then no adjustment would be possible, and quality would not be an issue. Generally, if all quality is fixed-by the tax statute or by natural constraints - and so only quantity is allowed to vary, then per-unit and ad valorem taxes are equivalent and would be treated correctly on the traditional rigid-quality framework. ${ }^{42}$

\section{Legal rules under variable quality.}

Turning now to legal rules, here too, rigid quality would imply no difference between legal rules that impose costs on a per-unit or an ad valorem basis. Rigid quality-either from perfect specification of attributes in the legal rule or from the natural unavailability of multiple, variable attributes-would imply the correctness of the traditional

41 Id at 1183; see also Leffler, $72 \mathrm{Am}$ Econ Rev at 957-60 (cited in note 6).

42 Barzel, $84 \mathrm{~J}$ Pol Econ at 1185 (cited in note 6); Kay and Keen, 19 Pub Fin Q at 242 (cited in note 6). 
quantity-price view of legal rules. But, in a world of positive measurement costs, quality changes do become an issue.

Although in many cases a legal mandate will provide some benefits to consumers and will impose some costs that are avoidable through quality changes, it is useful analytically to begin with the limiting case in which consumers do not value the mandated attribute at all. This case is not all that interesting in itself since it may be rare, but it is useful to consider it for analytical purposes: even where consumers do value the warranty somewhat, quality shifts of some sort may occur and serve to obscure how much value consumers do derive. In evaluating the effects of the warranty on price, quality shifts can produce noise in the signal.

For example, consider a law that mandates that toasters carry a warranty against faulty wiring. Say toasters that last one year cost $\$ 10$ without the warranty and $\$ 17.50$ with the warranty. Toasters that last two years cost $\$ 22.50$ without the warranty and $\$ 30$ with the warranty. ${ }^{43}$ Toasting services will now be cheaper with the longer lasting toaster ( $\$ 15$ per year) than with the shorter-lived one ( $\$ 17.50$ per year). This makes the toaster example just like the tax on light bulbs. Now, consider two respects in which the mandate can be different from the tax. First, the mandate may lead to efforts to improve the wiring on toasters: this is an example of what I call direct quality effects.

Now consider the second, indirect type of quality effect. Consumers may value the warranty (and the better wiring if that occurs). If so, the cost of the warranty will be lower and the consumer's valuation will be higher. Say that the marginal consumer values the warranty at $\$ 2.50$ regardless of toaster durability (an assumption made for ease of exposition that will be relaxed later ${ }^{4}$ ). Then the tax-like aspect of the warranty is only $\$ 5(\$ 7.50-\$ 2.50)$; note that the warranty is inefficient. Without the mandate consumers will not choose the warranty, but after the mandate they can buy either a one-year toaster that they value at $\$ 12.50$ for a price of $\$ 17.50$, or they can buy a two-year toaster that they value at $\$ 25$ for a price of $\$ 30$. Toasting services then cost $\$ 17.50$ per year with the low-quality (one-year) toaster and cost $\$ 15$ per year $(\$ 30 / 2)$ with the high-durability toaster. Again, we expect a shift toward more durable toasters even though these cost more (and are

43 The warranty might be more or less expensive per toaster as durability increases. I return to this issue shortly.

44 The analysis is complicated but not changed in any essential way if this assumption is dropped. A warranty could produce constant benefits if toasters of greater durability presented the same level of risk as a one-year toaster, say, because greater durability lessened the risk and hence the value of the warranty per unit of toasting services. For a more general analysis, see Part II.A. 
valued less) in the pre-mandate equilibrium. The excess of the warranty's cost over the consumer's valuation functions as a per-unit tax that may increase quality.

In the case of a non-cost-justified mandate, a competitive market can be expected to supply that combination of quality attributes that will minimize the sum of the net cost of the mandate (marginal cost minus marginal benefit), losses from decreased production, and losses from productive inefficiency. That is, with respect to the net cost that the mandate imposes, the quality response will work as in the case of an input factor price rise or an excise tax.

Notice too that in this example, the price of toasters has risen not just by the cost of the warranty (from $\$ 10$ to $\$ 17.50$ ), but by more than the cost of the warranty-by $\$ 20(\$ 30-\$ 10)$, which is greater than $\$ 7.50$. Interestingly, since the price increase is greater than the cost of the mandate it appears that more than the cost of the mandate has been "passed on," making the mandate look efficient. But by hypothesis, the mandate is inefficient: the price consumers pay for the warranty exceeds the value the marginal consumer places on it. Thus, variable quality can lead to price increases that look like the case of an efficient legal rule in which more than the full cost is passed on. This ambiguity has not been recognized because quality is assumed not to vary, but it is a potential problem, as I will show.

Indirect quality effects are not limited to legal rules that mandate features of a buyer-seller transaction. Many of the rules most clearly related to taxes are those that seek to internalize externalities. A Pigovian tax and a liability rule both aim to impose a.price on an externality; by making an actor pay for the harm caused, the externality is internalized. By contrast, property rules are backed up by sanctions: officials decide what entitlements are and violators are subject to a fine that causes their private costs to take a discontinuous jump at the point where the violation begins. ${ }^{46}$ That is, under property rules, actors are not subject to any officially imposed costs or punishments up to a certain point of an activity, but then are subject to severe costs or punishments after they pass that point, with the theoretical goal of the

45 See Parts II and V. Because this Article is about quality changes, it will focus on the results of mandating a feature of a product that was not provided by the pre-mandate market. Warranties themselves are used in part to solve informational problems where consumers find it costly to measure quality at the point of sale. See, for example, Barzel, $25 \mathrm{~J}$ L \& Econ at 32-34 (cited in note 4); George L. Priest, $A$ Theory of the Consumer Product Warranty, 90 Yale L J 1297,1303-07 (1981).

46 I am following the formulation in Robert Cooter, Prices and Sanctions, 84 Colum L Rev 1523,1524 (1984) (defining a sanction as "a detriment imposed for doing what is forbidden") (emphasis omitted). See also Guido Calabresi, The Costs of Accidents: $A$ Legal and Economic Analysis 68-69 (Yale 1970) (outlining framework of price-like specific deterrence and sanctionlike general deterrence); Part III. 
officials being to eliminate all of the harmful activity in excess of that point. The difference between the Pigovian tax and the liability rule is that in the former the government gets the money whereas in the latter victims are compensated. It is often thought that Pigovian taxes and liability rules possess a great advantage over property rules in that they require less information." Officials need only know the level of external harm to "price" it with a liability rule or Pigovian tax, but to use a property rule officials must know the right quantity of the externality, which can normally only be determined by weighing costs and benefits. Thus, the fact that pricing mechanisms like liability rules only require a proper subset of the information required for property rules is taken as a strong argument for liability rules.

But this view rests on an incomplete picture of quality changes. For example, consider environmental legislation that aims to reduce pollution by imposing a fee on factory emissions. Unsurprisingly, direct quality changes, such as use of abatement equipment, can make achieving the internalization of the externality less costly than otherwise. But indirect quality changes-those that simply reduce the incidence of the tax or legal rule to the private actor-can complicate the information costs. For example, if pollution from a set of firms consists of component $A$ and component $B$, and $A$ is the problem from current production, it might appear that pricing $A$ is superior than devising the quantity of pollution to allow (as under a property-rule approach). But this may not be true when two conditions hold: First, if the mix of components can be shifted towards $B$ especially at higher pollution quantities and, second, if measuring the amount of $B$ is more costly than measuring the amount of $A$. The property-rule approach will be superior where the costs from the shift in quality towards increased $B$ outweigh the consequences of errors in determining the allowable pollution quantity under the property-rule regime. In some cases, hybrid regimes will be called for, as we will see. ${ }^{48}$ In cases where the substitution is into something that itself produces externalities and where these are costly to measure, a Pigovian tax or liability rule may cause measurement costs to rise.

\section{Mandates}

Mandates are generally considered to be an alternative to taxation and public provision that can achieve similar goals. The advantage of a mandate is that it allows regulated individuals and entitles more flexibility in deciding how to achieve the goal set by officials. Public finance teaches that it is often useful to analyze a legal rule that im-

47 See note 83 and accompanying text.

48 See Part III. 
poses a mandate (such as a mandatory warranty on a product sold to consumers) as the equivalent in some sense of a "benefits tax" on the transaction. ${ }^{49}$ It is as if consumers are taxed and the revenue is spent on the product enhancement in question (for example, the warranty). Again, as several authors have recognized, the net rate of this tax is equal to the difference between the cost of the mandate and the value placed on it by the marginal consumer..$^{50}$ As in the example above, if a mandatory warranty adds $\$ 7.50$ to the cost of a toaster but the marginal consumer values the warranty at $\$ 2.50$, the equilibrium will change as it would to a $\$ 5$ tax on toasters - not as it would to a $\$ 7.50$ excise tax.

What this literature ignores is the possibility of variable quality, and in particular what I am calling "indirect" quality effects. If quality is assumed to be constant, then the tax-like component (the $\$ 5$ tax in the toaster example) will cause the same quantity shift and the same deadweight loss whether it is imposed on a per-unit basis ( $\$ 5$ per $\$ 10$ toaster as assumed in the example) or on an ad valorem basis (say, 50 percent of a toaster that otherwise costs $\$ 10$ ). But, once quality is allowed to vary, it may matter very much whether the $\$ 5$ tax-like component of the mandate is imposed on a per-unit or an ad valorem basis. The next sections take up in turn the cases of mandates with a perunit cost and those with an ad valorem cost.

\section{A. Per-Unit Mandates}

Consider now the case of a legal mandate that imposes costs on a per-unit basis. We need to be concerned with three sets of attributes.

49 See, for example, Summers, 79 Am Econ Rev at 180-81 (cited in note 12) (analyzing mandates as benefits taxes in transactions within a rigid-quality framework). See also, for example, Sam Peltzman, Toward a More General Theory of Regulation, 19 J L \& Econ 211 (1976); Richard A. Posner, Taxation by Regulation, 2 Bell J Econ \& Mgmt Sci 22 (1971) (arguing that regulation is used to redistribute wealth and can be considered a branch of public finance).

50 See, for example, Summers, 79 Am Econ Rev at 180-81 (cited in note 12) (stating that "mandated benefits represent a tax at a rate equal to the difference between the employer's cost of providing the benefit and the employee's valuation of it, not at a rate equal to the cost to the employer of providing the benefit").

51 In this section I extend the original Barzel tax model to include the warranty as a separate attribute. Barzel, $84 \mathrm{~J}$ Pol Econ at 1179-82 (cited in note 6) (considering a per-unit tax and its effects on specified characteristics, unspecified characteristics, and the commodity as a whole). For a more formal version of this extended model, see the Appendix. This extension increases the number of cases that need to be considered. The assumptions behind the Barzel model reduce its generality, see, for example, Kay and Keen, 19 Pub Fin $Q$ at 238-39 (cited in note 6); Leffler, $72 \mathrm{Am}$ Econ Rev at 964 (cited in note 6), but it does seem to capture the empirically most significant cases. (The same occurs in the case of the Alchian-Allen theorem.) As noted in the text, the additional possibilities precluded by some of the assumptions made here do not affect the main argument that recognizing endogenous quality makes the effects of a legal rule more complicated and the evidence must be regarded as more ambiguous than in the conventional rigid-quality framework. 
Into the first class fall those attributes that are specified in the legal rules; these include, for example, attributes used to define the "product" for which the legal rule mandates a warranty. In the second class are those attributes in the pre-mandate equilibrium product that are not specified by the legal rule; these are like the durability of the light bulbs or toasters in the examples above. In the third class are the mandated attributes themselves, for example, the nondisclaimable warranty.

To make things simple, I will assume that each of the attributesspecified, unspecified, and mandated-contributes to the marginal value of a product unit in a separable way. ${ }^{\text {s3 }}$ Also, I will concentrate on cases in which taxed attributes and untaxed attributes are either substitutes, independent, or (at most) weak complements; only strong complements are excluded. ${ }^{\text {st }}$ For now, I assume that all consumers have the same valuation (this will be relaxed later) and that there are no income or selection effects. These will sometimes be empirically reasonable assumptions, but at any rate they do not affect the main argument here. Unless all the adjustments cancel each other out, which is not likely, the possibility that there might be yet more complicated quality adjustments only reinforces the point made here: that quality changes will lead to greater ambiguity of results from legal rules than is usually thought.

In the equilibrium before the imposition of a legal mandate, each attribute's marginal contribution to the value of the commodity equals its marginal contribution to the cost of the commodity. The warranty will impose a marginal cost consisting of components that vary with the level of attributes other than the warranty and a fixed cost component once the product is chosen. Unlike with the usual per-unit tax,

52 Alternatively, the statute might use a word like "toaster" waiting for courts to fill in the meaning. Nevertheless, it is doubtful that every attribute, such as durability, will be incorporated into the definition of "toaster" regardless of the extent to which the definition is supplied by the legislature, administrative agencies, or the courts. However, these different institutions might favor different levels of detail.

53 That is, I examine an additive transformation of the supply schedules for each class of attributes. Relative levels of "untaxed" attributes remain the same (without any important loss of generality). For now, I also assume that there are no cross-effects or differential interactions between the attributes and commodities outside the "product" in question. These assumptions are commonly made in the literature following Barzel, $84 \mathrm{~J}$ Pol Econ at $1181 \mathrm{n} 7$ (cited in note 6), and they are the assumptions that have been found necessary to support the Alchian-Allen theorem. For a framework that drops some of these assumptions, see Leffler, 72 Am Econ Rev at 956 $\mathrm{n} 2,964-65$ (cited in note 6).

54 Otherwise an Edgeworth-paradox-like effect can arise, in which a tax on one attribute can cause a decrease in both that attribute and a strong complement, leading to an overall decrease in quality and price. See Leffler, 72 Am Econ Rev at 964 \& n 26 (cited in note 6).

55 That is, I assume that the tax-like component of the net benefits do not raise or lower income enough to affect demand. Also, for now I assume homogenous consumers and no unravelling through adverse selection. 
the marginal value of the warranty can be nonzero; the warranty confers a marginal benefit that likewise comprises a variable component and a fixed component. Now, with the imposition of the warranty, a new equilibrium will emerge at which the sum of the marginal costs of all the attributes (including the marginal cost of the warranty attribute) equals the sum of the marginal values of the attributes.

Two key differences between the legal rule and the excise tax become apparent. First, as mentioned earlier, unlike the tax, the warranty does not simply impose a cost with no corresponding benefit. Thus, the effect of the warranty appears on both sides of the equation of marginal benefit and marginal cost. Second, the levels of the attributes of the pre-mandate commodity can affect the cost and benefit of the warranty attribute. That is, in the case of the per-unit excise tax, once the product is chosen the tax level is constant (for example, $\$ 0.75$ per light bulb), but with a mandate such as a warranty, altering the level of attributes within the product itself can have an effect on the marginal cost and value of the warranty.

Returning to the three classes of attributes identified at the beginning of this Part, some of the $n$ attributes of the original commodity will be specified in the definition of the commodity for purposes of the legal rule but others will not (just as in the case of the tax). Thus of the $n$ attributes the first $k$ will be specified and $k+1, \ldots, n$ will not. For ease of exposition, the former, specified, attributes can be reduced to one composite attribute $A$ and the latter, unspecified, attributes can be grouped into composite attribute $B{ }^{5}$ At the new post-mandate equilibrium, the new price will equal the sum of the marginal costs of the attributes (specified, unspecified, and mandated) which will equal the sum of the corresponding marginal values.

At this point, results depend on the relative sizes of the various components of marginal benefit and cost. Most significantly, the issue is whether the warranty itself is less than, more than, or exactly costjustified. The following two subsections discuss these issues in greater detail and can be skipped without loss of understanding. Conversely, those seeking more formal versions of these arguments can find them in the Appendix.

56 Thus, I am modeling the interaction of the attributes with the warranty. This does seem to be empirically important, as noted in Part V.B.2. If necessary, similar treatment could be given to any of the original attributes that show similar interaction effects.

57 That is, the relative levels of the attributes within each set do not change. Without this assumption, the argument goes through but no additional insights are gained. 


\section{Non-cost-justified warranty.}

In this first case, the marginal value of the warranty is less than its marginal cost. This was the case in the toaster example above, ${ }^{58}$ in which the marginal consumer valued a $\$ 7.50$ warranty at $\$ 2.50$, for a $\$ 5$ tax-like excess. What makes this case interesting is that variable quality can make this case look deceptively more like one in which the mandated attribute, the warranty, has net value to the marginal buyer. Under the conventional view, the demand curve simply shifts up by less than does the supply curve. But what looks like such a shift in the demand curve may be the effect of increased quality as a cost-evading device.

Whenever a warranty with a per-unit cost structure is not costjustified, it does act like a tax in the sense that, under the assumptions adopted here, it will lead to a decrease in the quantity of the commodity as a whole, which in turn means that we move downward along the marginal cost curves of each of the attributes. ${ }^{59}$ That is, for these attributes, the situation is like that for the whole product in Figure 2A above: the demand (marginal value) curve shifts up by less than does the supply (marginal cost) curve, leading to a decrease in quantity and a corresponding move backwards down the marginal cost (supply) curve.

It is important to keep in mind that variable quality can manifest itself in both direct and indirect ways. Not surprisingly, altering the level of an attribute can make a warranty more or less costly, leading to what I will call the "direct" quality effect. For example, if a warranty is required on toasters, increasing the level of the wire insulation attribute may decrease the cost of the warranty. More indirectly, to the extent that the warranty is not cost-justified, it acts like a specific excise tax, which can lead to a cost-evading quality increase. In this latter, "indirect" case, the increase in quality does not directly make the warranty less costly per "unit" of the product (as defined by the law) but it does lessen its incidence. Through the quality shift, the same warranty cost per legal "unit" is concentrated on fewer but higherquality (in the example above, higher-durability) units.

In the Appendix, I consider a range of subcases of the non-costjustified warranty. Generally speaking, the possible quality effects of the non-cost-justified warranty outnumber those of the excise tax. There are three broad classes of cases. First, there might be no interaction between the level of $A$ attributes (specified and unspecified) and the cost of the warranty. If so, then the warranty acts like a per-unit

58 See text accompanying notes $43-45$.

59 That is, for each attribute the marginal costs are increasing, as they are in the case of the whole product in Figures 1 and 2. 
excise tax and we expect, if anything, a quality increase of the indirect sort. ${ }^{60}$

Second, what I will call the warranty effect-the net marginal contribution of the attribute to the value of the warranty-might be positive. If so, there will be an incentive to increase quality in a way consistent with the policy of the warranty. For example, wiring in a toaster might be improved in the presence of a mandated warranty. Thus, where the "warranty effect" of an attribute is positive there will be a trend for an additional direct quality change in addition to the pressure for indirect quality changes from the tax-like extra cost of the warranty.

Third, this warranty effect might be negative: the attribute contributes in a marginally negative way to the value of the warranty. One might think that there would be an incentive to reduce the attribute, and there is some pressure in this direction. But against this, we must consider the "product effect," the marginal contribution of the attribute to the value of the product. If one reduces the level of the attribute, by assumption this will reduce the cost of the warranty, but it may also destroy product value. The key is which of these happens faster. In the Appendix it is shown that depending on whether the positive product effect or the negative warranty effect dominates, we might get an increase or a decrease in quality. The possibilities are summarized in Table 1.

TABLE 1

NEGATIVE WARRANTY EFFECT

\begin{tabular}{|c|c|c|}
\hline & Product Effect Dominates & $\begin{array}{c}\text { Warranty Effect } \\
\text { Dominates }\end{array}$ \\
\hline $\begin{array}{c}\text { Unspecified } \\
\text { Attributes }\end{array}$ & $\begin{array}{c}\text { Appendix Case (d) } \\
\text { Quality increase but less } \\
\text { than for excise tax }\end{array}$ & $\begin{array}{c}\text { Appendix Case (e) } \\
\text { Quality decrease }\end{array}$ \\
\hline Specified Attributes & $\begin{array}{c}\text { Appendix Case (f) } \\
\text { No quality change }\end{array}$ & $\begin{array}{c}\text { Appendix Case (g) } \\
\text { No quality change }\end{array}$ \\
\hline
\end{tabular}

Within each class of attributes, unspecified and specified, different attributes may fall under different subcases. The net effect cannot be determined a priori, and the range of possible quality changes exceeds that for a per-unit excise tax.

60 See case (a) in the Appendix.

61 See cases (b) and (c) in the Appendix. 


\section{Cost-justified warranty.}

Here the marginal value of the warranty equals or exceeds the marginal cost. Consider the truly cost-justified warranty, whose marginal value exceeds its marginal cost. In part, this is the case discussed briefly above in which, for some reason like framing, the pre-mandate market equilibrium did not produce a warranty valued more than its cost. $^{62}$ In such cases, after the warranty is mandated the demand curve shifts outward by more than the supply curve does and we get a quantity and price increase. Can quality changes happen here too? Yes, because while the warranty may be overall cost-justified, it may impose costs on unspecified margins in one of two ways. First, the warranty can simply cause that attribute to be more costly (that is, to shift the attribute's marginal cost curve outward). Second, the quantity increase induced by the (overall valued) warranty can lead in the case of an individual attribute to a move beyond the point at which marginal cost equals marginal benefit for that attribute. That is, the quantity shift in the overall product causes a movement along the marginal cost curve for the attribute that results in a larger rise in cost than the corresponding additional benefit from movement down the marginal value curve.

Consider a mandated warranty on a toaster like that in the earlier example except that it is cost-justified overall. ${ }^{63}$ That is, again, a oneyear toaster costs $\$ 10$ without a warranty and $\$ 17.50$ with a warranty, and a two-year toaster costs $\$ 22.50$ and $\$ 30$, respectively. Suppose the marginal consumer values the toaster-warranty that costs $\$ 7.50$ at $\$ 9.50$, rather than at $\$ 2.50$ as before. In this case demand for the package would seem to shift outward by $\$ 2$. However, it might be the case that the warranty's costs are concentrated on a subset of the toaster's attributes in one of two ways. First, increasing the wiring safety attribute might cost $\$ 1$ but save $\$ 2$ in warranty cost, in which case that attribute will increase. Or, similarly, the warranty might make the presence of another attribute costly, such as a high-heat setting, which could be removed. These quality changes result from a shift upward of the marginal cost (supply) curve for the attribute. Second, the increase in quantity of toasters demanded will cause a shift upward along the supply curve of toasters. But if we think about a toaster as a collection of individual attributes, the marginal cost of certain attributes might rise faster than others. For example, the cost of a material or a component might become expensive - chrome plating grows scarce and costs $\$ 1$ more per toaster because of toaster demand-which might lead to a substitution within the "toaster" towards more plastic and fewer

62 See text accompanying note 24 .

63 See text accompanying notes $43-45$. 
chrome plated surfaces. This latter type of quality effect stems from a movement along the existing marginal cost curve of the attribute.

Finally, the marginal value of the warranty could equal the marginal cost. Here we have a wash: the demand curve shifts up just as much as the supply curve does. The result is no change in quantity, but an increase in price. Again, individual unspecified margins could require adjustment for the reasons just described in the previous case of the non-cost-justified mandate with per-unit cost.

\section{B. Ad Valorem Mandates}

Taxes may be levied on a specific ad valorem basis, and some legal rules can impose costs on products or services on what amounts to an ad valorem basis as well. As Barzel has shown, one should expect a specific ad valorem excise tax to tend to reduce quality. Attributes are subject to the tax only if they are part of the package. As long as separating attributes out of the package is less costly than the tax saved, they will be removed from the package. The "product" will decline in quality and price will be lower than expected in the rigidquality framework.

Similarly, when legal rules impose costs on an ad valorem basis, we should expect pressure towards lower quality from the incentive to separate out unspecified attributes from the product (or service). But, again, the impact of a legal rule is likely to be more complicated than that of the corresponding tax, because increasing the level of an attribute, specified or unspecified, can in some cases reduce the cost of what is otherwise an ad valorem mandate. A priori it is not clear whether the overall trend will be toward raising or lowering the level of an attribute (or of quality more generally). The effect of the ad valorem-type mandate that calls for lower quality to avoid the tax-like aspect can either be countered or reinforced. It is countered (wholly or partially) where there is an incentive to increase quality in order to lower the cost of the warranty. For example, increased safety through an increase in an attribute can, over some range, lower the cost of a warranty more than it adds to the ad valorem cost. On the other hand, the ad valorem effect can be reinforced when the reduction of an attribute not only saves the tax-like cost on that attribute but also lowers the cost of the warranty.

None of these effects is as surprising as the incentive for higher quality that comes from the mere imposition of a mandate with a perunit cost, ${ }^{65}$ but these effects do underline the difficulty in evaluating

64 See Barzel, $84 \mathrm{~J}$ Pol Econ at 1183-85 (cited in note 6). A general ad valorem tax on all commodities in the economy will not have this effect.

65 See Part II.A. 
the welfare and distributional effects of a legal rule that imposes costs on an ad valorem basis. More generally, we would also want to know in evaluating a rule whether it imposes costs on a per-unit basis, an ad valorem basis, or some combination of the two.

Consider the (generalizable) example of a warranty that imposes its costs initially on an ad valorem basis. For example, the legally mandated warranty provides for a nonwaivable repair remedy, and repairs are costly in proportion to the quality present in the product. This ad valorem legal rule imposes costs on attributes at rate $c^{w}$ and provides benefits at rate $v^{w}$.

The ad valorem tax and the legal rule that imposes costs on an ad valorem basis show some important similarities. Each makes lower quality attractive; reducing levels of $B$ allows some of the cost to be avoided because $B$ is only exposed to the cost of the rule as part of the product. Of course, as in the per-unit case, the value might exceed the cost $\left(v^{w}>c^{w}\right)$, in which case we would expect the shift outward in demand discussed by Craswell ${ }^{66}$ and emphasized in behavioral law and economics. ${ }^{67}$ But when the cost exceeds the value $\left(c^{w}>v^{w}\right)$, then the rule operates as a tax to the tune of the excess, that is, at the rate $c^{w}-v^{w}$. We expect that $B$ will be decreased to avoid the cost of the rule as long as any inconvenience of doing so is outweighed by the tax saved. If the pre-mandate benefit from selling $B$ as part of the package (as opposed to separately) is less than the marginal cost of the attribute times the net rate of cost, then $B$ may be dropped from the "product" completely.

There are several important differences between the legal rule with an ad valorem cost and the specific ad valorem tax. First, it is worth emphasizing that for the corresponding ad valorem tax, the analogue to $v^{w}$ would be zero-the tax does not contribute to utility. Second, unlike with the usual tax, the legal rule can impose different costs for different attributes. The cost of the mandate on each margin can be different and even unknown to the lawmaker.

Third, unlike a tax, the "tax rate" and "benefit rate" of the ad valorem cost imposed by a legal rule on an attribute might well depend on the level of that attribute: the cost and benefit rates are functions of attribute levels. Ad valorem taxes are not usually designed with anything other than a flat rate structure. By contrast, the legal rule can impose a progressive, regressive, or even negative rate structure on the attribute. ${ }^{68}$ In the case of a positive rate structure (even a progressive one), the result runs in the same direction as with the posi-

66 See Craswell, 43 Stan $L$ Rev at 370-71 (cited in note 1).

67 See, for example, Jolls, Sunstein, and Thaler, 50 Stan L Rev at 1505-08 (cited in note 3). fits.

68 The negative rate structure is just the case, again, where the legal rule presents net bene- 
tive flat-rate structure. For the regressive rate structure, there would only be an incentive to increase quality if the cost-lowering effect through the regressive rate-increased value leads to lower proportionate cost-outweighed the cost-increasing effect of having more $B$ around to tax. An example might be an "ad valorem" warranty whose cost could be avoided more effectively by an increase than by a decrease in quality.

Thus, the legal rule that imposes costs on an ad valorem basis tends to lead to lower quality, as does the ad valorem tax, but, unlike the tax, legal rules can impose benefits and can apply costs and benefits at different rates to different attributes. The situation of a legal rule that imposes a constant ad valorem "rate" of cost on all margins of a product is illustrated below in Figure 5.

FIGURE 5

Effects of an AD VALOREM Legal Rule

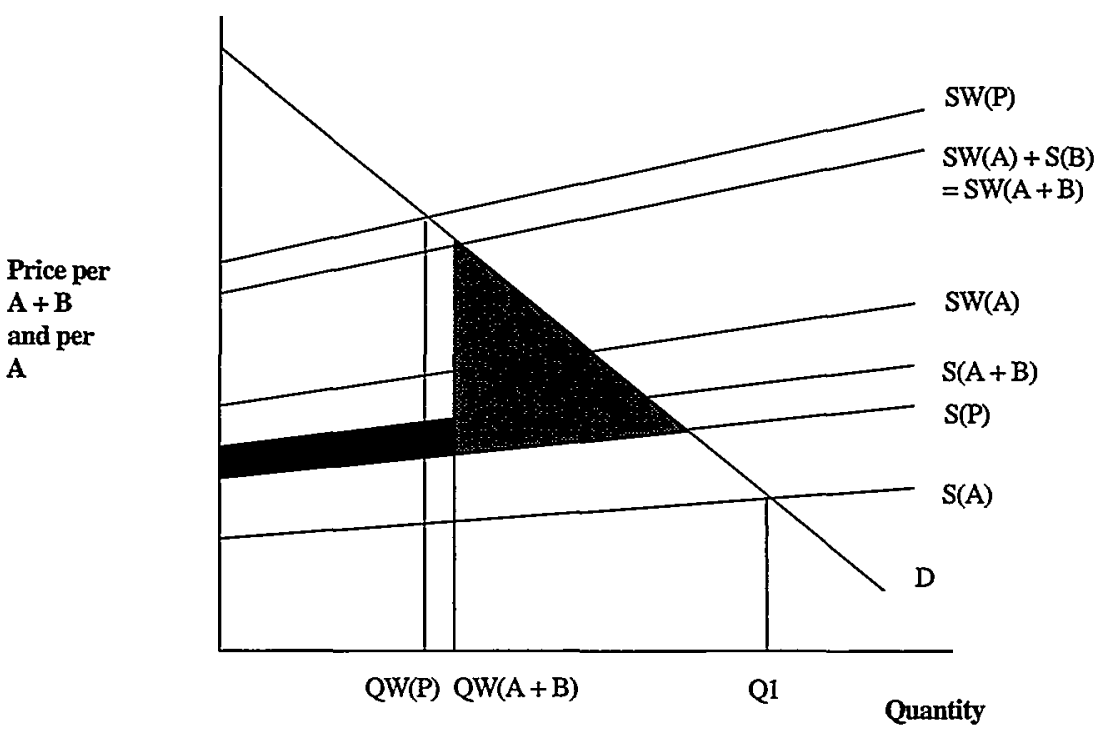

The pre-mandate supply curves are $S(A)$ for the supply of $A$ alone, $S(P)$ for the supply of the package that contains both $A$ and $B$, and $S(A+B)$ for the supply of $A$ and $B$ separately (the vertical sum of $S(A)$ and $S(B)$ ). Similarly, the corresponding post-mandate upwardlyshifted supply curves are $S W(A), S W(A+B)$, and $S W(\mathrm{P})$. The equilib- 
rium quantity after the mandate falls less with variable quality $(Q W(A+B))$ than expected on the rigid-quality framework $(Q W(P))$, because the supply curve for the (rigid) product shifts up more with the mandate than does the curve that is the vertical sum of the supplies of the separate attributes. Correspondingly, price rises less with variable quality than under rigid quality.

If the legal rule succeeded in defining the product completely, then there would be no incentive to reduce quality. For example, if the legal rule mandated that any sales of $A$ and $B$ for the benefit of the same consumer would be subject to the mandate, then the result would be no shift in quality. Not only is it costly to specify margins in this way, enforcement of the resulting rule likely would be administratively unworkable. In the case of legal rules with costs of either the per-unit or ad valorem type, the rigid-quality analysis would be appropriate if all margins were specified in the rule. Notice that, again, the ad valorem legal rule imposes a different deadweight loss than the corresponding fully specified legal rule implied by the constantquality framework. The welfare-loss triangle is smaller than under constant quality, but there is an additional component to the loss stemming from the effort to avoid the cost: here that extra component is the area from 0 to $Q W(A+B)$ lying between the $S(P)$ and $S(A+B)$ supply (marginal cost) curves. This extra component of loss reflects that, in the post-mandate equilibrium, each unit will be produced at the higher marginal cost of the separate $A$ and $B$. The overall welfare loss should be less than that imposed by the inefficient legal rule, but the rule will also likely have less of the intended effect (assuming a non-efficiency-related purpose). As in the case of the per-unit mandate, the ad valorem legal rule leads to ambiguous data. The extra price fall could be mistaken for a fall in demand and thus help mask any increase in demand stemming from the benefits of the legal mandate. ${ }^{69}$ Again, how much of a price drop reflects demand factors will tend to be obscured by the overlay of simultaneous quality changes induced by the legal rule in question.

\section{TAX-LIKE LIABILITY RULES}

In the preceding Part, I analyzed legal rules that were designed to favor buyers in a way that the pre-mandate market equilibrium fails to do. This Part extends the analysis to legal rules that are designed to in-

69 As for quantity, to the extent that it will be salient, quantity will decrease less under variable quality in a case like that illustrated. This can be interpreted as a shift (somewhat) outward in demand. As I argue in Part IV.B, it seems that price effects are more salient in this area than are quantity effects, and so confusion resulting from quality changes induced by the costs of a legal mandate is likely to take the form discussed in the text. 
ternalize "externalities," i.e., pricing instruments such as Pigovian taxes and liability rules. ${ }^{70}$ Liability rules differ from Pigovian taxes in that the amount levied is paid as compensation to victims under the liability rule rather than inuring to the public fisc. ${ }^{\text {n }}$ Liability rules, which seek to charge an actor with an amount approximating the cost of the external harm, also differ from property rules, which carry a strong penalty aimed theoretically at completely deterring unilateral taking of entitlements. ${ }^{n}$ Many commentators have advocated expanding the use of taxes or liability rules because of an important feature they share: Pigovian taxes and liability. rules "harness" private actors' information, leaving officials to determine who is the cheapestcost-avoider and the external costs that the individual or firm causes. ${ }^{3}$ In contrast, property rules require that officials determine the costs and benefits of a given activity themselves and set the optimal level of that activity accordingly. Thus, liability rules only require part of the information necessary to create a property rule. That taxes and liability rules require a proper subset of the information required to design a property rule is what I call the "informational-subset" argument. This informational-subset argument seems to be expanding in scope. Recently, some commentators have advocated liability rules over property rules for controlling externalities such as pollution, even where the exact level of harm is not known to officials. ${ }^{24}$

As I will show, this informational-subset argument depends on an assumption of rigid quality, and endogenizing quality renders the informational-subset argument problematic. Endogenizing quality leads to other interesting results here too, but ones that differ somewhat from the case of the mandate. Pigovian taxes (and liability rules) benefit from direct quality changes that make the cost of compliance with the legal standard lower, and this is a substantial component of what we expect from cheapest-cost-avoiders. But, as in the case of legal mandates, indirect quality changes may complicate the picture. ${ }^{75}$

70 See A.C. Pigou, The Economics of Welfare 172-203 (MacMillan 4th ed 1938). For a discussion of Pigovian taxes and references to the vast literature, see William J. Baumol and Wallace E. Oates, The theory of environmental policy 21-35, 42-47 (Cambridge 2d ed 1988).

71 Pigovian taxes are also beneficial to the extent that they reduce the need for distortionary taxes elsewhere in the economy. I will focus more on the comparison of liability rules and property rules, which have identical revenue effects of zero.

72 The article that introduced the liability rule versus property rule framework is Guido Calabresi and A. Douglas Melamed, Property Rules, Liability Rules, and Inalienability: One View of the Cathedral, 85 Harv L Rev 1089 (1972).

73 Cheapest-cost-avoider analysis was introduced into law and economics in Calabresi, The Costs of Accidents at 135-73 (cited in note 46).

74 Kaplow and Shavell, 109 Harv L Rev at 717-18 (cited in note 9); Louis Kaplow and Steven Shavell, On the Superiority of Corrective Taxes to Quantity Regulation, National Bureau of Economic Research Working Paper No 6251 *6-9 (1997).

75 Other arguments have been advanced in favor of liability rules; in what ways the possi- 
When the measurement of the externality is approximate, indirect quality changes may generate extra information costs for liability rules and in some cases can, surprisingly, make them inferior to regulation by direct control of quantity (i.e., by property rules). ${ }^{76}$ Indirect quality effects may explain why pollution retains its attractiveness as the classic example for advocates of liability rules and Pigovian taxes more generally." I end this Part with a discussion of subsidies, for which indirect quality effects pose special problems.

\section{A. Taxes, Externalities, and Direct Quality Effects}

We have already seen that the "excess cost" of a mandate can be viewed as an excise tax that may affect quality through transactors' efforts at minimizing the incidence of this tax-like burden. But there is a more straightforward and seemingly well known parallel between legal rules and taxes: both Pigovian taxes and liability rules (such as strict liability in tort) aim to charge actors with the external costs they impose. The two types of rules differ in who receives the levied amount: Pigovian taxes are paid to the government, whereas liability rules usually provide compensation for the victim. Pigovian taxes are not always an improvement; as is well known, the Coase Theorem holds that in an ideal world (specifically one without transaction costs), there would be no need for such taxes because costless bargaining would eliminate them. ${ }^{78}$ However, it is also true that in a zerotransaction-cost world a command-and-control economy would work too (planners would have complete information and orders would be costlessly given and carried out). Instead, transaction costs and government's costs (administrative, political) are both positive, and, in any given situation, the problem is how to minimize the total cost of organizing economic activity. I will focus on the effects of quality

bility of quality changes complicate these arguments is beyond the scope of this Article. See, for example, Ian Ayres and Eric Talley, Solomonic Bargaining: Dividing a Legal Entitlement to Facilitate Coasean Trade, 104 Yale L J 1027, 1036-72 (1995) (arguing that liability rules facilitate bargaining); Ian Ayres and Eric Talley, Distinguishing Between Consensual and Nonconsensual Advantages of Liability Rules, 105 Yale L J 235 (1995) (same); Louis Kaplow and Steven Shavell, Do Liability Rules Facilitate Bargaining? A Reply to Ayres and Talley, 105 Yale L J 221 (1995) (questioning the conclusions of Ayres and Talley).

76 Because in this section $I$ take the informational-subset argument as a starting point, I am following the convention in the literature on this argument of casting a choice between a quantity-based instrument backed up by a sanction on the one hand and pricing mechanisms on the other as one of property rules versus liability rules. This can sometimes be misleading. See notes 99 and 119.

77 See text accompanying notes $84-88$.

78 Ronald H. Coase, The Problem of Social Cost, 3 J L \& Econ 1 (1960).

79 See Steven N.S. Cheung, The Transaction Costs Paradigm: 1998 Presidential Address, Western Economic Association, 36 Econ Inquiry 514, 518-20 (1998) (arguing that in zerotransaction-costs world there would be no need for a market or property rights). 
changes as one piece of the overall picture that ultimately includes considerations of political feasability. ${ }^{80}$ Treating the question as one of choosing between instruments under unitary fiat is a useful analytical exercise to tease out the role that certain factors-here quality changes-play, and analysis should not stop with that (although this seems to be all too often forgotten). ${ }^{81}$ Examination of wider political concerns, despite its relevance to an analysis of a given regulation, is beyond the scope of this Article. In the next Part, I show how indirect variable quality leads to information costs that bear on the choice of legal instruments for regulating economic activity.

Before turning to the indirect quality effects, it is worth emphasizing that direct quality effects often reinforce the desired outcome of a Pigovian tax or liability rule. If a tax or a liability rule is designed to internalize an externality, we want the supply curve of a firm to shift upward by the cost that the activity imposes. The supply curve is the firm's marginal cost of production, and the tax is meant to shift this curve upward by the amount of the external harm remaining after cost-effective abatement measures have been taken, thus producing a new marginal cost curve that is the sum of the original marginal costs plus the marginal cost of the harm. A new equilibrium will be established at the intersection of this new supply curve and the demand curve. Consider Figure 3 in Part I.B.1 above. If the purpose of the tax or legal rule is to internalize an externality, then the shift upward would not be wasteful-as it was in the case of the mandate-but rather efficiency-increasing.

Quality changes-ones that I am calling "direct"-now lead to even greater efficiency. When Figure 3 is taken to depict a tax or rule aimed at an externality, a quality change that allows the supply curve to shift upward by less than it otherwise would is to be welcomed: such a direct quality change means that producers are internalizing the externality in an even lower-cost way than if they merely adjusted the production level. This is no great surprise: one of the merits of taxa-

80 On the politics of environmental law, see, for example, Thomas W. Merrill, Explaining Market Mechanisms, $2000 \mathrm{U}$ III L Rev (forthcoming) (discussing and synthesizing two models of instrument choice in U.S. environmental regulation); Jonathan Baert Wiener, Global Environmental Regulation: Instrument Choice in Legal Context, 108 Yale L J 677, 735-97 (1999) (discussing global environmental regulation under different voting rules and implementation structures).

81 The tendency of economists not to go beyond the benevolent despot model has been criticized. See, for example, James M. Buchanan, The Constitution of Economic Policy, 77 Am Econ Rev 243, 243 (1987) (arguing that economists "should look to the structure within which political decisions are made" when proferring policy advice).

82 In the new equilibrium, the tax will be the amount that would be optimal after costeffective abatement measures have been used. On the assumptions needed to guarantee Pareto optimality and convergence of tax rates with the optimal amount of the externality, see Baumol and Oates, The theory of environmental policy at 36-56,110-37 (cited in note 70). 
tion as opposed to command-and-control regulation is that it permits firms flexibility in how the external harm is factored into production, and direct quality changes can be viewed as one method by which firms can respond to the new price of the harm.

\section{B. Indirect Quality Effects and the Choice of Liability Rules}

When measurement is costly, however, quality changes can work at cross purposes to such Pigovian taxes and liability rules. It is often argued that "pricing" devices such as taxes and liability rules are superior to direct regulation and property rules because the information required to implement the former is a subset of the information needed for the latter: direct regulation requires officials to know and weigh both costs and benefits, whereas pricing requires only knowledge of benefits. ${ }^{83}$ Under pricing, economic actors-individuals or firms - can set the officially determined price against their own marginal costs; these "cheapest-cost-avoiders" will perform and act on the cost-benefit analysis. The informational-subset argument has been particularly popular in the literature on environmental externalities, with direct regulation of technology finding only modest support. ${ }^{85}$ For pollution, quantity-based regulation has found some favor among commentators, ${ }^{86}$ particularly among those in the Coasean or property-

83 Richard A. Posner, Economic Analysis of Law 414-15 (Aspen 5th ed 1998) ("[E]missions standards require cost-benefit analysis; pollution taxes require only benefit analysis."); Kaplow and Shavell, 109 Harv L Rev at 724-32 (cited in note 9); A. Mitchell Polinsky, Controlling Externalities and Protecting Entitlements: Property Right, Liability Rule, and TaxSubsidy Approaches, 8 J Legal Stud 1 (1979). See also Steven Shavell, Liability for Harm versus Regulation of Safety, 13 J Legal Stud 357,358-66 (1984).

84 Pigou originally proposed the taxation framework with pollution as a core case. Pigou, The Economics of Welfare at 29-30, 183-203 (cited in note 70). The approach has found many advocates. See, for example, Kaplow and Shavell, 109 Harv L Rev at 719 (cited in note 9). See also Posner, Economic Analysis of Law at 414-15 (cited in note 83); Polinsky, $8 \mathrm{~J}$ Legal Stud 1 (cited in note 83).

85 See, for example, Howard Latin, Ideal Versus Real Regulatory Efficiency: Implementation of Uniform Standards and "Fine-Tuning" Regulatory Reforms, 37 Stan L Rev 1267, 1271 (1985) (identifying "numerous advantages of uniform standards"); Thomas O. McGarity, Radical Technology-Forcing in Environmental Regulation, 27 Loyola LA L Rev 943, 944, 955 (1994) (arguing that in some instances banning an activity and forcing the development of new technology may be a superior method of regulation); Sidney A. Shapiro and Thomas O. McGarity, Not So Paradoxical: The Rationale for Technology-Based Regulation, 1991 Duke L J 729 (arguing that congressional regulation requiring the use of the "best available technology" is rational and compares favorably to market-related regulation).

86 See, for example, Baumol and Oates, The theory of environmental policy at 57-78 (cited in note 70) (arguing that in some instances quantity controls, such as tradable emission permits, may work better than price controls, such as Pigovian taxes); William J. Baumol and Wallace E. Oates, The Use of Standards and Prices for Protection of the Environment, 73 Swed J Econ 42, 42, 51 (1971) (finding that establishing standards for environmental quality and imposing unit taxes to achieve those standards may be more practical than levying a Pigovian tax); Martin L. Weitzman, Prices vs. Quantities, 41 Rev Econ Stud 477,477-79 (1974) (claiming that there is no universal rationale for preferring price controls over quantity controls); Gary W. Yohe, Towards a Gen- 
rule camp who propose quantity-based tradable permits. ${ }^{87}$ But even these proposals are susceptible to the critique from the informationalsubset argument for pricing. Notably, Louis Kaplow and Steven Shavell have argued that the informational argument for liability rules holds up even when courts have only a rough notion of average damage from an externality.

But this "informational-subset" argument loses its validity when the assumption of rigid quality is dropped: variable quality may cause the information costs associated with Pigovian taxes and liability rules to differ and in some cases those costs may be higher for the pricing mechanism than for regulation and property rules. The choice between the two depends in part on how large those information costs from variable quality are. Before turning to how indirect quality changes weaken the informational-subset argument, it is worth emphasizing that indirect quality effects need not always weigh against liability rules. Instead, indirect quality effects qualify the theoretical arguments for Pigovian taxes and liability rules and cause the data to be more ambiguous.

1. The informational-subset argument for liability rules.

One of the simplest and most enduring arguments for Pigovian taxes and liability rules, especially in law and economics, has been based on relative information costs. It is said that the information required to implement taxes and liability rules is a subset (usually proper) of the information required to devise controls and property

eral Comparison of Price Controls and Quantity Controls under Uncertainty, 45 Rev Econ Stud 229 (1978) (concluding that Weitzman's assertions are valid under less rigid assumptions). See also Susan Rose-Ackerman, Effluent Charges: A Critique, 6 Can J Econ 512 (1973) (criticizing the argument for effluent charges for failing to adequately consider real-world complexities and suggesting that non-market regulatory devices may be preferable); Michelle J. White and Donald Wittman, A Comparison of Taxes, Regulation, and Liability Rules under Imperfect Information, $12 \mathrm{~J}$ Legal Stud 413, 414-20 (1983) (comparing costs of taxes and controls in linear case in which uncertainty introduces an additive constant).

87 In his critique of Pigovian taxes, Coase proposed that property rights could internalize pollution externalities. Coase, $3 \mathrm{~J} \mathrm{~L} \&$ Econ at 1-2 (cited in note 78). As a method of implementing a property approach, commentators have advocated tradable emissions permits of a slice of an officially determined quantity of allowable pollution. See, for example, J.H. Dales, Pollution, property \& prices 93-97 (Toronto 1968) (describing possible market in pollution rights); T.H. Tietenberg, Emissions Trading: an exercise in reforming pollution policy (Resources for the-Future 1985); Thomas D. Crocker, The Structuring of Atmospheric Pollution Control Systems, in Harold Wolozin, ed, The Economics of Air Pollution: A Symposium 61, 81-84 (Norton 1966); W. David Montgomery, Markets in Licenses and Efficient Pollution Control Programs, $5 \mathrm{~J}$ Econ Theory 395 (1972); William O'Neill, et al, Transferable Discharge Permits and Economic Efficiency: The Fox River, $10 \mathrm{~J}$ Envtl Econ \& Mgmt 346 (1983); Thomas H. Tietenberg, Transferable Discharge Permits and the Control of Stationary Source Air Pollution: A Survey and Synthesis, 56 Land Econ 391 (1980).

88 Kaplow and Shavell, 109 Harv L Rev at 731-32 (cited in note 9). 
rules. For rules like the former that are designed to charge a fee for external harm, we need only know the marginal-or maybe even only the average ${ }^{89}$ - harm caused by a unit of the externality-producing activity. Charging that as a tax or liability will then induce the actor (say, a firm) to set that fee equal to its marginal costs of compliance by cutting back on the activity or abating its harmful effects. Because the firm or other actor knows its control costs better than officials, the tax or liability rule harnesses this information without the need for officials to develop it independently; instead, the officials have placed liability on the cheapest-cost avoider.

By contrast, property rules and controls set standards that are backed up by hefty sanctions. To implement these, the informationalsubset argument goes, officials need to know both the level of external harm and external benefit: officials are engaged in the cost-benefit analysis of the activity themselves. The information they require to do so will include the information about benefits required by taxes and liability rules, and some besides - the information about control costs that the taxes and liability rules "harness" from the private actors. Thus, in situations where control costs and external harms are not correlated, ${ }^{30}$ the information needed to implement taxes or liability rules is a proper subset of that required for control or property rules, and the former are predicted to do at least as well as the latter and usually better.

As is often the case, this argument makes some strong implicit assumptions about measurement costs. In situations where measurement costs are trivial or otherwise do not impact the two types of rules differently, the informational-subset argument has some appeal. And in the economics literature, it is often assumed that measurement costs will not significantly differ under the two regimes."

But there is no guarantee that measurement costs can safely be ignored in this way. Measurement costs can vary for a variety of reasons. In the next subpart, I concentrate on measurement costs in the presence of indirect quality changes. For now, note that taxes and liability rules can require a more costly measurement of marginal harm than do property rules. Under a property rule that says that one cannot engage in externality-producing activity more than $x$ units, to impose liability one only need satisfy oneself that the level of activity is greater than $x$. There will be some cases in which the level is clearly

89 Id at 727.

90 Id at 727 n $43,777$.

91 Again, this is partly due to the tacit assumption that quality is constant. For a particularly clear example of how the tacit assumption of constant quality leads to abstracting away from measurement costs in the pollution context, see Baumol and Oates, The theory of environmental policy at $164 \mathrm{n} 10,168-69$ (cited in note 70). 
above $x$, particularly if $x$ is zero (i.e., the rule allows none of the activity). Consider speeding: charging speeders (or even speeders who get into accidents) with the marginal cost of each mile per hour of speed requires more measurement than does a rule that sets a limit, say 55 miles per hour. Cars going 100 miles per hour are clear violators and no more than eyeball measurement would be needed.

Louis Kaplow and Steven Shavell have recently argued that these costs will not favor property rules. ${ }^{92}$ They claim that even using expected harm as an approximate measure would be enough to lead one to prefer liability rules. This can be interpreted in any of three ways, none of which takes measurement costs very seriously. Kaplow and Shavell might be claiming that we should charge average expected harm where we do not know with precision the exact level of harm, but they are assuming that we have good information on exact levels of activity (speeding in my example, pollution in their main example). Or they may assume that this latter measurement problem - the metering problem-is not significant in absolute terms. Or they may not see it as important in relative terms; perhaps in their view metering costs will not differ much from liability rules to property rules.

Any of these three assumptions is questionable. The significance and relative size of metering problems presented by liability and property rules are simply empirical questions that no amount of a priori reasoning will decide. This becomes especially apparent when we turn to the effects of indirect quality changes.

\section{Informational effects of variable quality.}

Variable quality can lead to information costs that differ from those under rigid quality, and if quality is allowed to vary, the simple informational-subset argument for liability rules no longer holds. Actual taxation of externalities requires that they be measured to some degree. Individuals and firms cannot be charged with the level of harm that they cause unless we can measure that level. If this measurement is costly, it will not be cost-effective for officials to pursue measurement to the point of complete accuracy. In other words, there can be a divergence between the measured level of harm and the actual level of harm. Some scholars have argued that this does not affect the case for Pigovian taxes and liability rules as long as there is no bias in such errors: Pigovian taxes and liability rules are superior to direct regulation and property rules as long as our use of expected average harm is not systematically biased upward or downward from actual harm.

92 See Kaplow and Shavell, 109 Harv L Rev at 719 (cited in note 9).

93 See, for example, id at 731,776-77. 
And, it is assumed, there is no reason to think that such biases pose difficult problems.

This view rests on the unstated assumption, common in the literature, that quality is rigid. For if quality is allowed to vary, errors of measurement take on more significance. In particular, where measurement is by proxy or where measurement of all the components of a harmful externality are not equally easy to measure, the indirect quality effects discussed above in connection with the mandated product enhancement can work at cross-purposes to the legal rule. If quality can vary, then an approach to externalities based on Pigovian taxes or liability rules can be less cost-effective than one based on property rules, because the latter may preclude indirect quality effects at lower cost than can the tax or the liability rule.

Now consider the classic example of the legal response to pollution again. Firms produce a quantity of good $(q)$ and in the process cause harmful emissions or effluents. For simplicity and without loss of generality, this pollution is made up of two attributes, $A$ and $B$. These attributes correlate with the level of environmental damage and can range from levels of harmful chemicals to the speed of emission to the height of a smokestack. These attributes can also be indexes that correlate with harm, such as biochemical oxygen demand ("BOD") as a measure of an emission's organic waste load. ${ }^{95}$ BOD is widely used as an index of harm from effluents, but it is approximate at best: emissions that are low in BOD can nevertheless contain high levels of harmful inorganic pollutants." Sometimes "pollution" is measured using such approximate measures as BOD. ${ }^{97}$ Or activity level or output itself can be used as a proxy for the amount of harm from emissions."

94 See, for example, Baumol and Oates, The theory of environmental policy at 170 (cited in note 70). A higher smokestack can sometimes disperse emissions, reducing their harm, but can also lead to acid rain. See, for example, id; Ralph Turvey, On Divergences between Social Cost and Private Cost, 30 Economica 309,312 (1963). 70).

95 See Baumol and Oates, The theory of environmental policy at 162 \& $\mathrm{n} 4$ (cited in note

96 Id at $162 \mathrm{n} 4$.

97 In one well known example, uniform water quality standards for the Delaware River Basin were based almost exclusively on BOD. United States Department of the Interior, Federal Water Pollution Control Administration, Delaware Estuary Comprehensive Study: Preliminary Report and Findings (1966). See also Latin, 37 Stan L Rev at 1275-76 \& n 33 (cited in note 85). The study and the resulting command-and-control regulations were criticized for excessively focusing on BOD and largely ignoring other types of pollution. Bruce A. Ackerman, et al, The Uncertain Search for Environmental Quality 28-29, 137-38,209-10 (Free Press 1974).

98 For example, in the regulation of volatile organic compounds, emissions are "measured" by multiplying reported activity by emission factors instead of monitoring actual emissions. This can lead to substitution towards paints and solvents with actual emission rates higher than those on which the calculated emissions factors are based. Dale B. Thompson, Political Obstacles to the Implementation of Emissions Markets: Lessons from RECLAIM, 40 Nat Resources J (forthcoming 2000). 
It is such approximate measures that can lead to undesirable quality changes in response to pricing-style regulation.

Consider a hypothetical case in which the regulatory authority can accurately measure $A$, but $B$ is difficult to measure. At current, pre-regulation production levels and methods, attribute $A$ is a chemical component or index that correlates with harm, and the amount of $B$ emitted by competitive firms causes minimal damage. If an effluent charge is imposed on $A$, the component that is currently harmful but easy to measure, then firms with different control costs will react differently. Now suppose that firms with high-control costs could use an alternative technology that emits more $B$ relative to $A$. This is much like the case of the per-unit tax discussed above: units of the externality are defined in terms of $A$, and a per-unit charge, whether by tax or liability rules, is imposed on these units. Under variable quality, we should expect a trend towards more $B$ relative to $A$ : the tax on $A$ makes the use of $B$ relatively cheaper. Firms will cut output and increase $B$ : this is an increase in "quality" from the firm's point of view, but from society's point of view this is a decrease in (environmental) quality. Specifically, the increased use of $B$ presents officials with an uninternalized externality or, alternatively, with more measurement costs. By hypothesis, attribute $B$ is costly to measure, and thus in this situation a rule will lead to greater costs the more it causes firms to increase $B$.

Now either taxing $A$ or limiting its quantity could lead to substitution in the direction of relatively more of attribute $B$. The measurement costs posed by such adjustments could take on different sizes for the two types of rules because $A$ and $B$ are not equally costly to measure: this alone conflicts with the simple informational-subset argument.

Moreover, the problems of indirect quality adjustments may differ depending on the level of $A$ used. If so, then a quantity-based instrument like some property rules can be used to constrain $A$ to a level at which indirect quality adjustments towards hard-to-measure $B$ are kept down. A particularly important case is the one in which the use of $B$ is subject to scale economies: only a firm that uses high amounts of $A$ will find it worthwhile to substitute toward $B$ when $A$ is taxed or constrained. This will not always be true, but, again, even the possibility of differential ease of substitution at different production

99 Broadly speaking, quantity-based regulation could take the form of command-andcontrol, quantity ceilings, or tradable permits. With tradable permits, problems of indirect quality changes similar to those arising under pricing instruments in the scenario in the text might require additional quantity limits on individual firms or on certain trades. In other words, the more that indirect quality changes are important, the more the firm-level quantity-limiting aspect of quantity-based instruments can become attractive. 
levels is enough to show that the simple informational-subset argument does not hold under variable quality. And to the extent that the cost of determining ranges where substitution occurs less easily is small relative to other information costs, like actually measuring $B$ itself, the case for quantity-based instruments over pricing instruments is strengthened. In such cases, the welfare loss from the liability rule can be greater, as illustrated in Figure 6.

\section{FIGURE 6}

Property RULe Versus TaX OR LiabiltTy RULE

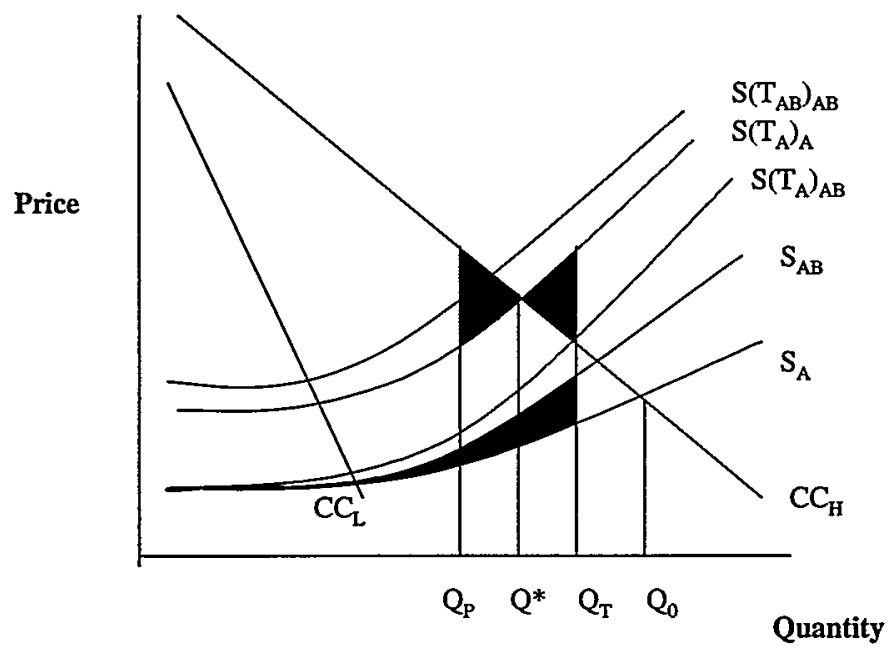

In this figure, the $S$ curves are firms' marginal costs of production (supply curves), and the $C C$ curves are marginal pollution-control cost curves. The $C C$ curves can be thought of as denoting marginal benefits from polluting because firms control pollution by foregoing those benefits. $C C_{H}$ is for firms with high marginal control costs (high marginal benefit) and $C C_{L}$ corresponds to firms with lower levels of such costs. The discussion will focus on the firms with high control costs, for whom the regulations are the most binding, but it should be kept in mind that regulators will often have very imperfect information about where firms' control cost curve actually lie. This uncertainty will figure in the analysis to follow.

As is usual, it is assumed that, as quantity produced increases, marginal costs and harms increase (rising $S$ curves) and marginal con- 
trol costs (benefits) decrease. $S_{A}$ represents the marginal harm from production using the production method that results in $A$-type pollution, and $S_{A B}$ denotes the marginal harm from the production method with a substantial component of $B$. In the unregulated equilibrium, the former $A$-type production will be chosen over the $A B$-type because it costs less ( $S_{A}$ lies below $S_{A B}$ at all points). For firms with high marginal control costs, this pre-regulatory equilibrium is characterized by amount $Q_{o}$ where $S_{A}$ and $C C_{H}$ meet. Now if a Pigovian tax (or liability rule) is imposed on $A$, which is not costly to measure and which presents the current problem, $S_{A}$ will shift upward to $S\left(T_{A}\right)_{A}$. But because the price on the externality is imposed on a per-unit basis on $A$, the supply curve for $S_{A B}$ under the tax (or liability rule) does not shift up as far, only to $S\left(T_{A}\right)_{A B}$. Firms will now chose the $A B$-type production method. This will impose a deadweight loss (not counting revenue effects) of the black triangle and the other black-shaded area, the latter representing the waste from using the more costly production method for all units up to $Q_{T}$ By comparison, quantity control will be characterized by some error; here it achieves quantity $Q_{P}$ ("quantity under property rule") which falls short of the optimum $Q^{*}$. But, in this example, the error cost from the property rule, represented by the gray triangle is less than the loss from the pricing instrument (Pigovian tax, liability rule) because it avoids the substitution possibilities within the "activity" of polluting.

One solution to the problems of the Pigovian tax or liability rule would be to institute a tax on $B$ as well. This would raise the $S_{A B}$ curve not just to $S\left(T_{A}\right)_{A B}$ but to $S\left(T_{A B}\right)_{A B}$. Now firms will choose the $A$-type production and because of the tax on $A$, they will produce the optimum, $Q^{*}$. But, by hypothesis, measuring $B$ is more costly than measuring $A$. The question is whether it is cost-effective to incur measurement costs in order to move the $S\left(T_{A}\right)_{A B}$ towards $S\left(T_{A B}\right)_{A B}{ }^{100}$ There is no a priori reason for this to be so. In other words, with endogenous quality, property rules and quantity regulation can be more efficient than Pigovian taxes or liability rules. ${ }^{101}$ Specifically, the informational-

100 This could take several forms, all of which are potentially costly. Definition of the "activity" can be refined to include level of $B$ or the type of production process. Or punitive damages could be used to adjust for a low probability of detection, but this requires measurement of the probability of detection. Nor is the awareness that $B$ is a problem sufficient to guarantee a low-cost measurement of its full extent: one can be fairly certain that substitution from B causes problems greater than the error costs (including estimation costs) under the quantity instrument without being able to come up with an unbiased estimate of the damage from $B$. That is, the "first" units of damage may be easier to perceive than "Iater" ones, leaving the tail of a problem of a size that is costly to measure.

101 Note that instituting a Pigovian tax or liability rule with an eye to achieving a certain quantity level makes such devices into quantity-based instruments. Conversely, what appears to be a quantity-based instrument can really be a pricing instrument if the level of quantity allowed is set based on the price that permits fetch in the market. 
subset argument does not go through in its simple form if quality is allowed to vary.

This caveat holds particularly true with liability rules based, as Kaplow and Shavell advocate, on average expected harm. ${ }^{102}$ The reason for choosing average expected harm is the difficulty of measuring harm to victims in particular cases. ${ }^{103}$ But it is in precisely these circumstances that we need to be worried about the quality of activities shifting. Substitution among rigidly defined activities is not the only problem: hard-to-measure substitution within activities can cause liability rules, particularly those based on average expected harm, to become unattractive. Put differently, the possibility of indirect quality changes makes less plausible Kaplow and Shavell's crucial assumption that courts' estimates of average expected harm need not be downwardly biased. ${ }^{104}$ The analysis suggests that in some cases, inaccuracy in the standard for quantity regulation that misses the optimal quantity is worth incurring if it allows one to avoid the measurement costs or externalities presented by increased use of $B$.

The problem identified here with liability rules bears some resemblance to scenarios examined in both the property rights and agency theory literatures. As a matter of property rights, two parties contracting over an asset will leave some margins unpriced because delineating and enforcing property rights to them is not worth the cost, and the unpriced margins will lead to efforts by those with access to the asset to try to capture the value of these undefended attributes. ${ }^{105}$ Thus, in a contract between a landowner and a farmer, the farmer will have an incentive to shirk under a wage contract, and the landowner will have an incentive to underprovide improvements to the land under a rental contract. In addition, under the rental contract (especially for a short term), the farmer may have an incentive to overuse soil nutrients. The choice of contract will reflect a trade-off among the losses from these incentives to capture unprotected wealth. In addition, the nature of the contract can serve partially to protect against opportunism even where such behavior cannot be observed

102 Kaplow and Shavell, 109 Harv L Rev at 731 (cited in note 9).

103 Other objections to using average as opposed to marginal harm have been identified. See, for example, Colin Read, The Marginal Agent and Judicial Intervention in the Marketplace, 30 Conn L Rev 647, 663-64 (1998) (concluding that average harm rule will deter some efficient retakings by original entitlement holders); Carol M. Rose, The Shadow of The Cathedral, 106 Yale L J 2175, 2193-97 (1997) (analyzing liability under average harm rule as a common-pool problem in some circumstances).

104 Kaplow and Shavell, 109 Harv L Rev at 730-31, 776-77 (cited in note 9). More precisely, there will be situations in which the downward bias is sufficiently large and costly enough to remove (by measuring $B$ ) that the property rule will be more efficient.

105 See, for example, Yoram Barzel, Economic Analysis of Property Rights 44-48 (Cambridge $2 \mathrm{~d}$ ed 1997). 
directly. In the land contract, the landowner could restrict the supply of water, which is a complement of soil nutrients in such a way as to make overuse of the nutrients less attractive. ${ }^{106}$ More generally, the furnishing of substitutes or the restricting of complements to an attribute that is costly to measure can be the most cost-effective method of stemming losses along those margins. ${ }^{107}$ To anticipate somewhat, liability rules and Pigovian pricing schemes can be analogized to the rental payment-a negative payment-in the landowner-farmer contract. Liability rules will need to be supplemented or supplanted when measurement problems become relatively large along other margins.

The issue of the relative ease of measurement along various margins has recently been analyzed more formally in the agency theory literature. Agency theory originally centered on an agent who was to perform one task, but it has now expanded to consider the much more interesting (and realistic) situation in which the agent faces multiple tasks that compete for her effort (or a multi-dimensional task whose dimensions present competing demands for effort). ${ }^{108}$ In multi-task agencies the relative ease of measurement can put a limit on the use of incentives. Examples include teachers who are expected to teach facts and (harder-to-measure) analytical techniques. ${ }^{109}$ Incentives based on test scores that reflect the former can cause a substitution away from effort at the latter, hard-to-measure margin, leading to suboptimal effort. Other examples include workers who must both produce volume and good quality or who must produce output and care for the machines they use to produce it. Wages tied to volume of output can lead to suboptimal effort on other margins that are costlier to measure, such as quality of output or care for the machine. ${ }^{110}$ In such situations, incentives cannot be tied too directly to the easy-tomeasure component of output, or the structure of tasks and asset ownership might be altered, ${ }^{111}$ or increased measurement in some form must be undertaken. ${ }^{12}$

106 Id.

107 Id at 48. See also Henry E. Smith, Semicommon Property Rights and Scattering in the Open Fields, 29 J Legal Stud 131,161-67 (2000) (analyzing boundaries as prices or sanctions).

108 See, for example, Bengt Holmstrom and Paul Milgrom, Multitask Principal-Agent Analyses: Incentive Contracts, Asset Ownership, and Job Design, $7 \mathrm{~J} \mathrm{L,} \mathrm{Econ,} \mathrm{\&} \mathrm{Org} 24$ (Special Issue 1991) (claiming that a model incorporating multiple tasks or multi-dimensional tasks of the agent can explain numerous features of the principal-agent relationship); Bernard SinclairDesgagné, How to Restore Higher-Powered Incentives in Multitask Agencies, $15 \mathrm{~J} \mathrm{L,} \mathrm{Econ,} \mathrm{\&} \mathrm{Org}$ 418 (1999) (discussing compensation of agents with multiple, difficult-to-measure tasks).

109 Holmstrom and Milgrom, $7 \mathrm{~J} \mathrm{~L}$, Econ, \& Org at 25 (cited in note 108).

110 Id.

111 The hard-to-measure task might be assigned to another agent, especially one with a residual claim on output.

112 Holmstrom and Milgrom, $7 \mathrm{~J} \mathrm{~L}$, Econ, \& Org at 50-51 (cited in note 108). SinclairDesgagné interestingly suggests that under certain circumstances higher-powered incentives can 
Some of the measurement issues involved in a pricing scheme can be illustrated by the results of a study by Don Fullerton and Thomas C. Kinnaman on residential garbage pricing. ${ }^{113}$ Several communities have instituted a price per bag for pick up of garbage from residences. The aim of the program is not just to raise revenue, but also to internalize the costs of garbage to the homeowners. This led to the "Seattle Stomp," so-called after the response to Seattle's early unit-pricing program, whereby homeowners would expend great effort compacting their own garbage in order to reduce the incidence of the per-bag fee. This effort is a social waste because garbage will be compacted by collectors anyway. By studying data on garbage from individual households in Charlottesville, Virginia, a town that adopted a per-unit fee in 1992, the authors were able to establish that in response households reduced the volume of garbage (by stomping) but did not necessarily reduce much the weight of garbage. Indirect evidence pointed to a small increase in recycling and some illegal dumping. ${ }^{114}$

From our point of view, measurement costs can explain many features of garbage pricing. First, and most clearly, pricing garbage on a per-unit of volume basis increased the "quality" (weight) of each garbage bag, but at a social cost. Thus, volume is an $A$ (specified) attribute, and weight is a $B$ (unspecified) attribute, and pricing $A$ means more of attribute $B$. Crucially, although Fullerton and Kinnaman's study is not concerned with measurement-cost explanations, $B$ here is difficult to measure relative to $A$ : weighing each household's garbage would give a much better index of costs that ideally would be internalized, but weighing is much more costly than counting bags. Moreover, social costs include the locks that commercial dumpsters need to be fitted with in order to prevent use by residents and the costs of cleaning up garbage dumped in wooded areas, ${ }^{115}$ but these can be regarded as part of the measurement and enforcement costs along other margins when units of volume are priced..$^{116}$ If garbage volume is

be restored in multi-task agencies by linking the auditing of the hard-to-measure task with success in the easy-to-measure task; this converts effort on the tasks from being substitutes to being complements. Sinclair-Desgagné, $15 \mathrm{~J} \mathrm{~L}$, Econ, \& Org at 418, 424-26 (cited in note 108). As Sinclair-Desgagné himself notes, this method is meant for purposes of internal monitoring and the audits it requires are not costless. Id at $430-31$. For our purposes, it is sufficient to note that the measurement costs attributable to the use of liability rules would be those characteristic of the least-cost monitoring system. In some cases, the least-cost monitoring system might involve audits, but whether this would render liability rules more cost-effective than quantity-based rules or other alternative methods for constraining actors remains an empirical question, as argued in the text.

113 Don Fullerton and Thomas C. Kinnaman, Household Responses to Pricing Garbage by the Bag, 86 Am Econ Rev 971 (1996).

114 Id at $978-80$.

115 Id at $978-80,982$.

116 The authors estimated that the programs were not cost-effective given the easily meas- 
priced, these margins will require increased monitoring, the costs must be endured, or measures that depart from Pigovian taxes must be used. ${ }^{117}$ Even the seeming triviality and obviousness (ex post) of these problems reinforces the theme of this Article. If such clear quality and measurement problems as stomping and illegal dumping were overlooked in traditional Pigovian analysis of this problem-as they were $^{118}$ - then more complex examples like consumer product warranties, air pollution, and other areas are all the more likely to result in misdiagnosis because of quality effects.

More generally, behavior along a margin that is difficult to measure can be influenced by restricting access to goods that are complements of that margin or by facilitating access to goods that are substitutes of that margin. Generalizing on our pollution example, the increased incentive to engage in $B$-type pollution that results from pricing $A$-the undesirable indirect quality change-might be addressed in several different ways. If $B$ can be monitored cheaply, then it could be priced. If $B$ is costly enough to measure, restrictions on a complement $C$, which is easier to measure, or subsidies for substitute $D$, which causes less harm, could be used to address $B$-type pollution. In our hypothetical, the scale of output can be thought of as a complement to $B$; by restricting scale through a quantity-based instrument, $B$ can be brought under control. In this special case, the quantity of component $A$ might be regarded as the complement to the hard-tomeasure $B$. Limiting the quantity of $A$ is the cost-effective method of preventing $B$-type pollution.

Liability rules can be thought of as a negative "wage" for engaging in a certain activity. Where the overall activity of the actor has multiple dimensions that are not all equally easy to measure, then quality becomes a factor in the choice of regulatory instrumment. The use of a pure pricing scheme on a dimension can lead to increased activity along other margins that are difficult to measure. In our hypothetical, charging for $A$-type harm can lead to a use of $B$ that did not make sense before. Now officials have a classic monitoring trade-off:

ured administrative costs, and admitted that they "[could not] begin to estimate" some of the other costs such as those from increased illegal dumping. Id at 982.

117 For example, some communities have even tried a one-bag-per-week minimum, which Fullerton and Kinnaman assume will reduce illegal dumping by one bag for those already dumping. Id at 980-81. However, the one-bag minimum may act somewhat like a quantity ceiling in our pollution hypothetical; by not marginally pricing the first bag, economies of scale in dumping may be lost, thus reducing substitution to hard-to-measure margins like dumping. This benefit must be weighed against the reduced incentive to reduce garbage below one bag per week.

118 Fullerton and Kinnaman point out that Repetto et al's previous study of garbage pricing ignored illegal dumping. Id at 981, citing Robert Repetto, et al, Green Fees: How a Tax Shift Can Work for the Environment and the Economy (World Resources Inst 1992). 
the cost of the harm from $B$ can be reduced but only by increased monitoring effort. However, this choice only arises if officials price $A$.

Overall, pricing $A$ must be compared with other methods of constraining the actor's behavior. Continuing the principal-agent analysis, the agent's actions can be influenced by placing incentives on a given activity or by placing or removing constraints on alternative activities. In the public context of liability, activities can be priced or their alternatives can be addressed through sanction-like constraints. In our hypothetical, quantity regulation serves this latter function. The general issue is whether the information costs (including expected error costs) from using quantity-based constraints are larger or smaller than the extra monitoring costs that arise from the indirect quality effect of the liability rules. ${ }^{119}$

The point about the informational requirements of liability rules is one of second-best theory in its broadest sense. ${ }^{120}$ At its most general, the theory of the second best holds that internalizing any one given externality need not be overall efficiency-increasing if other distortions remain, because the distortion eliminated may have been counteracting another distortion. When quality is allowed to vary, such second-best considerations can arise for reasons of measurement cost. Internalizing an externality along one dimension can cause measurement costs to rise along other dimensions, even those that are not apparent in the pre-regulatory environment (as was $B$-type pollution in our hypothetical). When this measurement cost is taken into account, there is no a priori reason to suppose that internalizing the cost of an easy-to-measure component of an activity will lead to greater overall efficiency.

This analysis also suggests the desirability of hybrid systems over pure pricing or pure control measures in some cases. A system of Pigovian taxes, liability rules, or even tradable emissions permits could be combined with quantity-based ceilings. ${ }^{121}$ Ceilings would be advis-

119 There will be times when seemingly obvious measures of quantity will lead to large measurement costs as well. For example, limiting a catch of fish based on weight, even under tradable permits, can lead to fishers discarding smaller fish at sea already dead and retaining only the proportionately higher-priced large fish which are then measured under the quota at dockside. See Carol M. Rose, The Several Futures of Property: Of Cyberspace and Folk Tales, Emission Trades and Ecosystems, 83 Minn L Rev 129, 170-71 (1998) (discussing this and similar examples in hunting and water pollution).

120 The theory of the second best was first put forward in Richard G. Lipsey and Kelvin Lancaster, The General Theory of Second Best, 24 Rev Econ Stud 11 (1956-57). See also Richard S. Markovits, Monopoly and the Allocative Inefficiency of First-Best-Allocatively-Efficient Tort Law in Our Worse-Than-Second-Best World: The Whys and Some Therefores, 46 Case W Res L Rev 313 (1996) (applying the theory of the second best to tort doctrines).

121 Other hybrids of pricing and quantity-based restrictions have been proposed in order to deal with error in pricing in short-term emergencies, see, for example, Alan J. Krupnik, Wallace E. Oates, and Eric Van De Verg, On Marketable Air Pollution Permits: The Case for a System of 
able where we suspect that quality changes in the upper ranges of pollution output would lead to large measurement costs-actually undertaken or in the form of uninternalized $B$-type pollution-under price-based approaches. The ceiling could eliminate much of the need to worry about the very elastic users who would engage in harmful indirect quality changes in order to reduce the incidence of the pricing.

Considering variable quality suggests some (very partial) explanations for the popularity of pricing mechanisms among some commentators and the suspicion toward them amongst regulators. Pollution is used as the paradigm case for Pigovian taxes and even for liability rules in part because we feel that pollution is easier to measure than some other activities. This intuition is not contradicted by the failure of liability-based pollution control programs because of the scarcity of actually implemented non-quantity-based pollution pricing schemes. ${ }^{12}$ Polluters are likely to know far more about the opportunities to substitute away from taxed attributes in the direction of other possibly quite harmful attributes that are costly to measure..$^{123}$

The analysis based on variable quality does not imply that quantity regulation will always or even often be superior to Pigovian taxes or liability rules. All it suggests is that the question cannot be decided by a priori reasoning as in the informational-subset argument. And the analysis suggests that as actors become more "elastic" in their activities, we have to start worrying about the measurement costs in dealing with the relevant substitutes.

Pollution Offsets, $10 \mathrm{~J}$ Envir Econ \& Mgmt 233 (1980) (arguing for a system of tradable emissions permits subject to a restraint of no air quality violation at any receptor points), or to limit consequences of error under uncertainty in estimating quantities, see, for example, Robert A. Collinge and Wallace E. Oates, Efficiency in pollution control in the short and long runs: a system of rental emission permits, 15 Can J Econ 346, 352-53 (1982); Marc J. Roberts and Michael Spence, Effluent Charges and Licenses Under Uncertainty, 5 J Pub Econ 193 (1976).

122 Limited programs involving tradable permits have been tried, but these are quantitybased programs, not Pigovian taxes: the regulator decides beforehand how many such permits to create and then lets a market price emerge. See, for example, Daniel J. Dudek, Richard B. Stewart, and Jonathan B. Wiener, Environmental Policy for Eastern Europe: Technology-Based Versus Market-Based Approaches, 17 Colum J Envir L 1, 18-45 (1992) (discussing tradable permit programs for plant and utility emissions, leaded gasoline, water pollution, development rights, and fishing); Robert W. Hahn and Gordon L. Hester, Marketable Permits: Lessons for Theory and Practice, 16 Ecol L Q 361, 366-96 (1989) (analyzing marketable permit programs in emissions, leaded gasoline, and water pollution).

123 Indeed, this analysis may suggest a reason-in addition to those identified in the political economy literature-why regulators are so suspicious of Pigovian taxes: Regulators, rightly or wrongly, might suspect that their lack of knowledge puts them at a disadvantage, and variable quality can play a part in creating that situation. Effluent charges are used in Germany, but unlike Pigovian taxes they are based on an assessment of the expected performance of best practicable technology. See, for example, 'Gardner M. Brown, Jr., and Ralph W. Johnson, Pollution Control by Effluent Charges: It Works in the Federal Republic of Germany, Why Not in the U.S., 24 Nat Resources J 929, 933-49 (1984). 


\section{Subsidies}

Subsidies are often thought of as negative taxes, but subsidies have their own effects, which variable quality can exacerbate. To achieve a given policy objective, mandates and subsidies are treated as the main alternatives to government provision. Subsidies can be given to consumers or to producers. Traditionally analysis has focused on several similarities and differences. Under conventional analysis, the main allocative problems with subsidies are that they encourage entry and discourage exit and that the taxes to fund them cause deadweight losses. Variable quality reinforces this conclusion: even firms whose entry or exit decisions are not affected by the subsidy will have an incentive to alter quality to increase the incidence of the subsidy. The losses from these quality shifts are expected to be even greater than those in the case of taxes and mandates.

1. Subsidies under rigid quality.

At first glance, under rigid quality, subsidies and mandates look deceptively close to being mirror images of each other, particularly on the consumer side. A mandate can be thought of as the equivalent of a subsidy financed through a tax in the amount of the difference between the cost of the provision and the buyer's valuation. The tax here is like a benefits tax in that it is tied to the amount of the benefit received. This is to be contrasted with a benefit financed out of general revenue. On the subsidy side, the type of subsidy that comes closest to being a mirror image of mandates is one that is earmarked for a given type of purchase, unlike a more general subsidy like welfare payments or a refundable credit under a negative income tax. Under rigid quality a subsidy is just a negative tax, and the subsidies that are targeted to certain commodities or services would closely correspond to the tax-like aspect of legal rules that consumers value at less than cost.

When it comes to taxes and non cost-justified legal rules, rigid quality will cause the distinction between per-unit and ad valorem cost structures to disappear. If quality cannot change, the same "commodity" is preserved through all stages of analysis and all we need inquire into is the elasticities of supply and demand. Likewise, when subsidies are provided but quality is not allowed to vary (by assumption, or, in the rare case, perhaps in fact), it would not matter whether a subsidy provides benefits on a per-unit or an ad valorem basis. ${ }^{124}$ Thus, a subsidy of 50 cents per meal that happens to cost $\$ 5$ would be the equivalent of a 10 percent subsidy on meals. The subsidy is just like the tax, the transportation charge, or the "excess" cost of the legal 
mandate (a warranty, for example), only the sign has been reversed; a subsidy is a negative tax.

Now consider subsidies that are designed to remove an externality. For example, firms could be given an amount of money for reducing pollution. The problem with such subsidies is that they are usually worse than Pigovian taxes. ${ }^{125}$ The subsidy can encourage excessive entry by firms and discourage exit, because to qualify for the subsidy one has to be a polluter. ${ }^{126}$ It turns out that in a competitive setting, a subsidy will reduce individual firms' emissions, but can be expected to increase overall emissions by the industry because now there will be more polluters. ${ }^{127}$ In principle, this distortion could be removed by decoupling eligibility for the subsidy from the entry-exit decision: one could theoretically give a subsidy to both actual and potential polluters. But such efforts would lead to unacceptable levels of administrative and political costs.

\section{Subsidies under variable quality.}

If, however, quality is allowed to vary, the similarity between subsidies and taxes breaks down even further. We might expect that, as in the case of taxes, variable quality causes per-unit and ad valorem subsides to diverge. This is partially correct. As Barzel has also shown, under variable quality, taxes and subsides are not just mirror images of each other; a subsidy behaves differently and leads to more distortion than the corresponding tax. ${ }^{129}$

Consider a constant per-unit subsidy on a commodity. If the demand and supply curves are linear and the subsidy rate equals the rate of the tax, the adjustment and the corresponding welfare-loss triangle are larger in the case of the subsidy. The quality change reinforces the

125 Baumol and Oates, The theory of environmental policy at 211-34 (cited in note 70). See also Wiener, 108 Yale $\mathrm{L} J$ at $726-27$ (cited in note 80 ).

126 Baumol and Oates, The theory of environmental policy at 212-13, 215-33 (cited in note 70); David F. Bramhall and Edwin S. Mills, $A$ Note on the Asymmetry between Fees and Payments, 2 Water Resources Res 615,615 (1966).

127 Baumol and Oates, The theory of environmental policy at 234 (cited in note 70); Wallace E. Oates, Economics, Economists, and Environmental Policy, 16 E Econ J 289, 290 (1990). If the subsidy causes a change in technology, overall emissions may be reduced, but the subsidy can still be shown to be inferior to a Pigovian tax alternative. Wiener, 108 Yale $\mathrm{L} \mathrm{J}$ at $727 \mathrm{n} 187$ (cited in note 80); Robert E. Kohn, When Subsidies for Pollution Abatement Increase Total Emissions, $59 \mathrm{~S}$ Econ J 77, 84-85 (1992). See also Stuart Mestelman, Production Externalities and Corrective Subsidies: A General Equilibrium Analysis, 9 Envir Econ \& Mgmt 186, 191 (1982).

128 Baumol and Oates, The theory of environmental policy at 216-17 (cited in note 70). It would be enormously costly for officials to determine which firms really are in the marginal position with respect to entry or exit. Firms would have an incentive to use resources to convince officials or politicians that they will pollute unless given a subsidy.

129 Barzel, $84 \mathrm{~J}$ Pol Econ at 1190-93 (cited in note 6). 
effect of the subsidy. Barzel compares a per-unit tax on light bulbsthe situation in Figure 3-to the per-unit subsidy depicted in Figure 7..$^{130}$

FIGURE 7

Per-Unit Subsidy

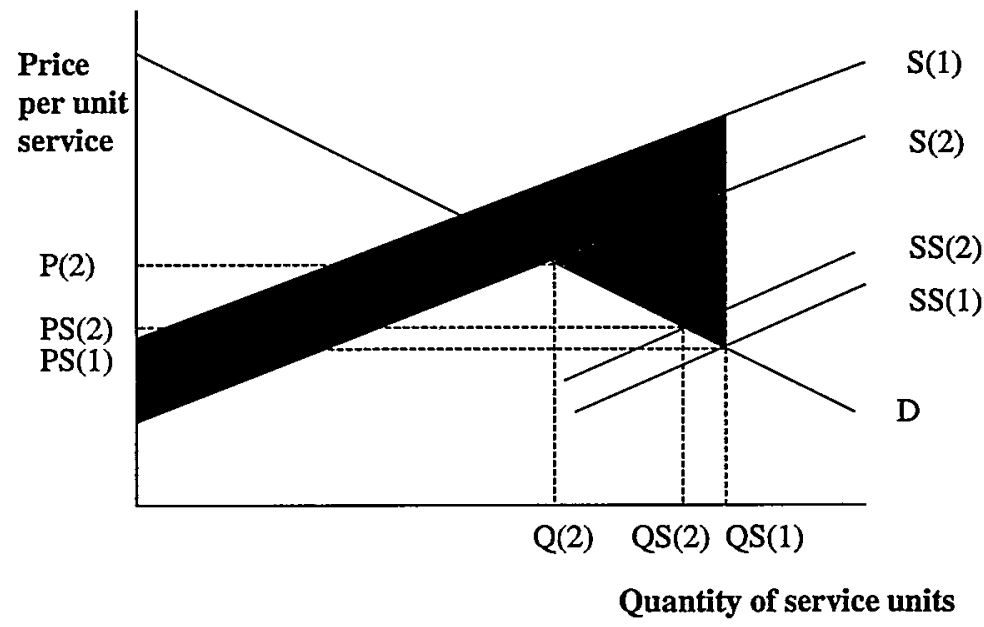

In Figure 7, $S(1)$ denotes the marginal cost (supply) of less durable light bulbs on a per unit of service basis, and $S(2)$ the supply of more durable light bulbs. Before the subsidy, higher durability is cheaper per unit of lighting service than is lower durability $(S(2)$ is less than $S(1)$ ), which results in an equilibrium with high durability at price $P(2)$ and quantity $Q(2)$. With the subsidy, the supply curve for lesser durability shifts downward more than does the supply of higher durability. Under the subsidy, marginal cost of lesser durability (SS(1)) is lower than the marginal cost of higher durability $(S S(2))$. Correspondingly, the equilibrium under the subsidy will be for low durability at price $P S(2)$ and quantity $Q S(2)$. This new price is lower and the quantity is higher than if quality had been constrained to the original higher durability, which would have resulted in $Q S(1)$ and $P S(1)$. As before, the light-shaded area is the deadweight loss triangle, and the dark-shaded area is the greater production costs incurred on each unit in order to achieve the extra subsidy per unit of lighting service. 
Here the subsidy causes a quality shift against durability: light services are cheaper per service unit with the subsidy if the durability is shorter (in the example, one month rather than two months). Suppose now that two-month bulbs are cheaper to make than one-month bulbs; with no subsidy (or tax) one-month light bulbs cost $\$ 1$ and twomonth bulbs cost $\$ 1.75$. Two-month bulbs will be chosen, because lighting services are cheaper per month that way $(\$ 0.87$ (\$1.75/2) versus $\$ 1$ per month). Now if a per-unit subsidy of $\$ 0.75$ is provided per bulb, the one-month variety costs $\$ 0.25$ and the two-month variety costs $\$ 1$. In that case, monthly lighting services cost $\$ 0.25(\$ 1-\$ 0.75)$ with a one-month bulb and cost $\$ 0.50((\$ 1.75-\$ 0.75) / 2)$ with a twomonth bulb, and so the one-month bulb will be chosen; the subsidy has caused a shift against durability in order to maximize the subsidy per unit of lighting services.

What is most interesting is that if quality is not allowed to vary the welfare triangles under the tax (Figure 3) or the subsidy (Figure 7) are equal, but if quality can vary, the subsidy leads to a larger welfareloss triangle. The subsidy causes the welfare-loss triangle to extend all the way to $Q S(1)$ rather than only to $Q S(2)$. In both cases, the tax or the subsidy causes a movement down along the demand curve. Quantity is therefore greater than in the case of rigid quality. This would mitigate the effect of a tax (which causes "too little" of the commodity to be purchased), but it exacerbates the effect of the subsidy: the subsidy will cause the "too much" to become even greater.

Now consider the implications of this analysis for consumer subsidies. Again, we might be using a subsidy to correct an externality. In the case of the Pigovian tax, quality effects reinforced the benefits of the tax except where measurement was approximate enough to allow indirect quality changes that did not reduce the externality. The subsidy can suffer similar problems: where we decide to subsidize a commodity but consumers value attributes that are not part of the definition of the commodity, we can expect indirect quality changes that may not accord with the subsidy's purpose. If light bulbs presented a positive externality (say reduced crime) and we wanted to subsidize them for that reason, a subsidy per light bulb would cause more deadweight loss than a subsidy based on "light-bulb services" would. But that is just another way of stating that we could eliminate the problem of indirect quality effects by better definition. This is only realistic where measurement costs allow better definition at less cost than the distortions thereby removed. In practice this will be difficult: even in the case of such a simple commodity as a light bulb, consumers may value not only light output and durability, but size, shape, number (for decorative arrays of lights), etc. Measurement costs, not definitions per se, present the challenge. 
An ad valorem subsidy would present further problems. One problem would be the open-ended nature of the subsidy and the worry that transactors are inflating the price. ${ }^{131}$ Also, here there would be an incentive to increase quality (the opposite quality change from the decrease expected under an ad valorem tax). But now we have the additional problem that transactors will have an incentive to increase levels of attributes that may not have even been present in the product in the pre-subsidy equilibrium. Thus, even if measurement and tracking of all the pre-subsidy equilibrium attributes were costeffective, this effort might not suffice. The possibility of new attributes being added will raise the measurement costs involved in ad valorem subsidies, and make them that much less attractive.

Similar problems arise on the producer side when considering subsidies versus Pigovian taxes and liability rules to correct externalities. Under conventional analysis, it is thought that for firms that would engage in the same types of activities under either taxes or subsidies, taxes and subsidies will have the same allocative effect on their decisions. ${ }^{1.2}$ But if we allow quality to vary, firms' output can be affected by a subsidy differently from the tax, even if the firm is not on the margin with respect to the entry-exit issue. The subsidy can lead to additional distortion from decisions made about the levels of attributes within a type of activity, not just whether the activity is undertaken at all. ${ }^{133}$

\section{Substitutions and Measurement Costs}

At this point one could claim that the problem with conventional analysis is that it needs a more fine-grained notion of "activity." could decompose an activity like producing shoes into many activities including using certain chemicals, locating in a certain place, etc. This misses a more important point: that measurement costs are likely to be greater when the levels of attributes within what is conventionally thought of as an "activity" are changed. One of the reasons we see some things as "activities" for purposes of conventional analysis and not others is that they are easier to measure. It is easier to measure the number of shoes produced than the levels of all the subactivities in-

131 That is, the subsidy would be particularly problematic if it were a percentage of the sales prices, which could be manipulated. The net flow of money might be more difficult to monitor than the flow of goods.

132 Baumol and Oates, The theory of environmental policy at 215 (cited in note 70).

133 That is, just as a subsidy potentially affects the entry-exit issue more than does a tax, so too a subsidy can have an extra effect on the entry or exit of an attribute.

134 This would be a bit like the use of more fine-grained commodities or market analysis in consumer theory. As mentioned earlier, this often does not take into account that measurement costs are not the same for all such "commodities." See note 5 and accompanying text. It is measurement costs, not the level of definition for analysis, that are crucial. 
volved in making them. What a framework based on variable quality suggests is that there is no a priori reason to exclude from analysis the response in terms of constituent subactivities. Unless ease of measurement correlates very well with likelihood of occurring (for which there is no guarantee), then quality changes can be important to policy analysis.

\section{AMBIGUITIES FROM ENDOGENOUS QUALITY}

Before turning to some applications of the analysis of variable quality, it is worth pointing out some previously unrecognized ambiguities that can result from variable quality in the case of "per-unit" legal rules that do not arise from excise taxes. In special cases where the attributes in question and the mandated warranty do not interact, the effects of legal rules on endogenous quality are exactly the same as those of per-unit excise taxes. Since this model is an extension of the excise tax model, this is to be expected. However, I argue that legal rules are more complicated than taxes in several respects. First, not only can the mandated attributes (on the model here) contribute something to the value that consumers place on the product, the levels of other attributes can also affect the cost or benefit of the mandated attribute. Thus, quality increases and decreases are possible, and the range of possibilities for legal rules is even greater than that for excise taxes. I show that these quality shifts can lead to data from inefficient mandates and legal rules that are similar to data reflecting efficient legal rules.

\section{A. Ambiguities in Per-Unit Mandates}

The case of quality increases due to the imposition of a non-costjustified warranty is particularly interesting, because the results can appear much like those of a valued warranty. I will show that quality changes can cause observational equivalence between two radically different situations. For example, a price rise and a quantity drop can reflect a mandate that is valued by consumers but not as much as it costs, or the price rise and drop in "units" as defined by the legal rule may reflect a quality increase that partially evades the cost of a legal rule that is valued less (or not at all) by consumers. (Later we will consider cases in which cost-evading quality changes can cause price to rise by more than the cost of a legal rule, thus partially mimicking the situation in which the market failed to provide an efficiently mandated feature.)

As we will see, excessive focus on changes in price (or sometimes quantity) in the wake of a legal mandate is perilous. A price rise (or a less-than-expected price fall) can stem from either a warranty that is 
valued (or valued somewhat) or it can stem from a shift to higher quality. Such a shift to higher quality can happen even if the warranty is not valued by the consumers, and indeed such shifts can occur even where the mandate is not valued as part of the product at all. In this latter, "limiting" case, the mandate does behave like an excise tax but nevertheless leads to price being higher than expected on the conventional constant-quality tax analogy.

Some of the difficulties stemming from variable quality can be illustrated graphically. Ambiguity in price and quantity can simultaneously arise in the case of an induced shift in quality, if we extend the analysis of the light bulb case. Consider a legal mandate that imposes costs on a per-unit basis characterized by the supply and demand curves in Figure 8.

FIGURE 8

Quality ShIFT Versus Demand ShIFT

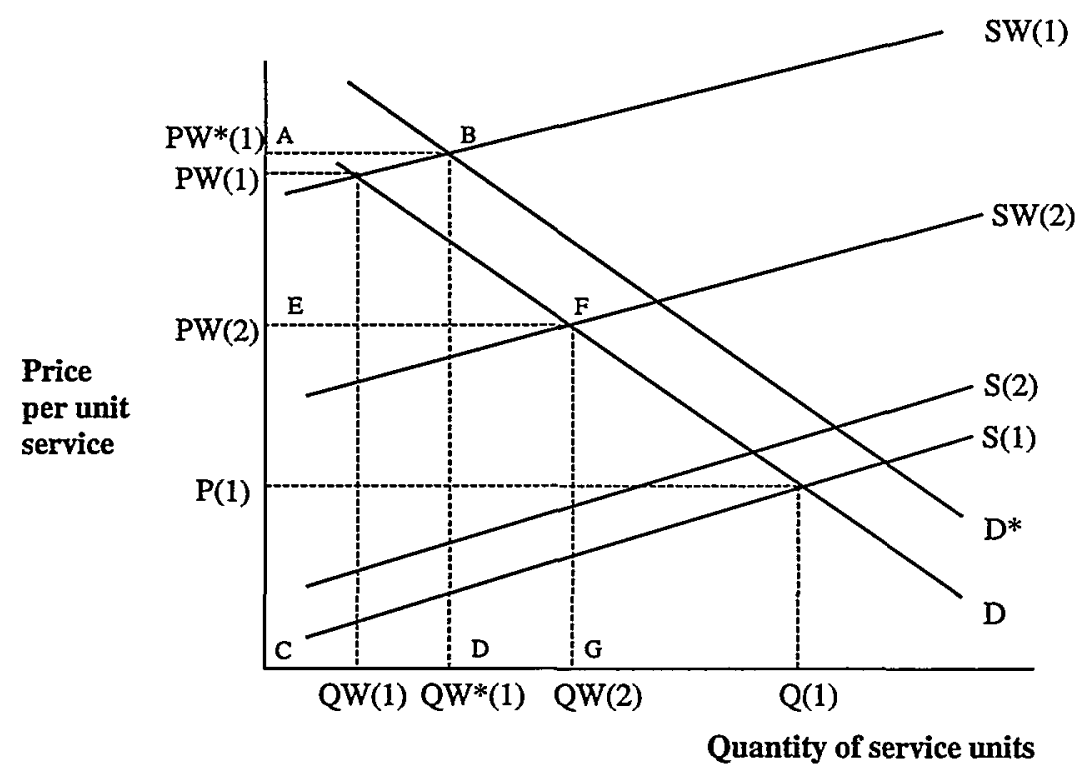

Both price and "quantity" are given here on a per-unit-of-service basis. But "quantity" as specified in the legal rule and for the purpose of data collection is measured on a per-unit-of-product basis, requiring a conversion of the per-unit-of-service units here to obtain the "quantity" per-unit-of-product in terms of which observations will be made. The curve $S(1)$ represents supply of the product of a given quality 
(here duration). The higher durability is not preferred because it costs more, as reflected in the higher $S(2)$ supply curve. When the mandate (say a warranty) is imposed, the supply curve for lower quality shifts upward by more than the supply curve for higher quality, leaving $S W(2)$ lower than, and hence preferred to, $S W(1)$. As can be seen, on a per-unit-of-service basis, the new equilibrium quantity is higher and price is lower than we would expect with rigid quality $(Q W(2)>Q W(1) ; P W(2)<P W(1))$.

But now consider what happens if we measure "quantity" on a per-unit-of-product basis, as the legal rule does. This will be quite normal, because the legal rule will reflect the least costly understanding of how to measure the product. When higher quality will result in a need for fewer units-as it clearly does in the case of increased durability ${ }^{135}$-the apparent quantity and price shift will be greater than they are on a per-unit-of-service basis. That is, if as is the case in Figure 8 , the new high quality is a durability 50 percent greater than that of the product in the pre-mandate equilibrium, the quantity $Q W(2)$ will appear the same as quantity $Q W^{*}(1)$ measured on a per-unit-ofproduct basis, even though $Q W(2)$ is 1.5 times $Q W^{*}(1)$ measured on a per-unit-of-service basis. For example, if $Q W(2)$ is 150 service units, these units are packaged in "product units" that are more durable and so will seem to be 100 "product units." Thus the 150 service units of $Q W(2)$ will "look like" the 100 service units of $Q W^{*}(1)$, which are packaged in a way that looks like 100 "units" for purposes of the statute. If we fail to distinguish units of differing durabilities, then $Q W(2)$ will appear to equal $Q W^{*}(1)$ : each represents 100 "units." Likewise the price $P W(2)$ will be concentrated on higher quality units and will appear the same as a price for low-quality units of $P W^{*}(1)$, even though $P W^{*}(1)$ is 1.5 times the price $P W(2)$ measured on a per-unitof-service basis.

Thus, high quality price and quantity $((P W(2), Q W(2))$ will look deceptively like the prices for a low quality item $\left(P W^{*}(1), Q W^{*}(1)\right)$, and, importantly, the latter could have resulted from a demand shift under an assumption of constant quality. The data on price and quantity could reflect $\left(P W^{*}(1), Q W^{*}(1)\right)$, which would result from a shift upwards in demand from $D$ to $D^{*}$ as indicated by the intersection of $S W(1)$ (the rigid-quality upwardly-shifted supply curve) and the hypothetical demand curve $D^{*}$. That is, unless quality is measured in a more fine-grained way than the legal rule provides for, the case of increased quality but an unvalued warranty will look the same as that of a somewhat valued warranty on a product of rigid quality. When the

135 Similarly in the case where one high-quality unit provides services at a faster rate than a lower-quality unit. 
two cases will look alike, the area of the box $A B C D$ will equal that of the box CEFG and vice versa. ${ }^{136}$

Not all cases will result in such an exact equivalence. But the closer the two boxes are in area, the easier will be confusion between the rigid- and variable-quality analyses. Furthermore, the more error in empirical studies of the pre- and post-mandate market data, the more the confusion illustrated here will arise in approximate fashion. Finally, in actual cases, even more will be going on. The choice will not be between an analysis of a valueless warranty with variable product quality and an analysis in terms of warranty value with rigid quality. Instead, often there will be a mixture of a demand shift due to value from the warranty and a quality shift to avoid its excess costs. Telling how much each effect contributes to the observed data will be challenging.

The situations of valued mandates and quality shifts from relatively unvalued mandates are theoretically distinguishable, but in practice the evidence will be difficult to interpret. I return to this question and its implications for welfare and equity, ${ }^{137}$ but for now note that there are two main ways to tell the difference and neither is likely to be straightforward. First, more sophisticated econometric techniques might be brought to bear on the data, but this would make large informational demands. ${ }^{138}$ Second, under the assumptions used here, in the case of a shift to increased quality where the mandate is not valued overall, we do expect a decrease in quantity, which could theoretically be used to help disambiguate the data. In the case of the valued warranty, we expect an increase in quantity. But, again, the problem is the measurement costs in defining units for quantity analysis. Further, policymakers, seeking to avoid a large allocational impact from a legal rule, will tend to choose commodities and services that have a relatively inelastic.supply. If so, the quantity shift will be difficult to spot, particularly where other factors bearing on supply and demand will infect the data used.

The problem more generally is that identifying the relevant supply and demand curves is difficult to begin with, but with variable quality this problem becomes much more so. Furthermore, the market leaves some margins unpriced (although reflected in price) and the

136 The quantities and prices will appear exactly the same in the low and high quality cases when $C D=a \times C G$ and $G F=C E=a \times D B=a \times A C$ (where $a$ is some constant). If so, then $A C=$ $1 / a \times G F$ and the area of the box $A B C D$ is $C D \times A C=(a \times C G) \times(1 / a \times G F)=C G \times G F$, which is the area of the box $C E F G$. Conversely, where the two points appear equal when measured by physical units (rather than by unit of service), the ratios $C G / C D$ and $C A / C E$ will be equal, making the areas of the boxes equal.

137 See Part V.A.

138 See notes $152-54$ and accompanying text. 
lawmaker leaves some margins unspecified in laws and regulations for the same reason: that it is costly to measure such attributes, important though they are. The more costly such margins are to measure, the more difficult they will be to incorporate into an econometric analysis of the effect of the legal mandate.

\section{B. Ambiguities in Liability Rules}

Similarly, quality changes can cause liability rules to look deceptively attractive. Where it is relatively costly to measure an attribute that can be increased in response to a pricing instrument (Pigovian tax, liability rule), quantity will fall less than it would under rigid quality. In Figure $6, Q_{T}$, the quantity in response to the tax on $A$-type pollution, is to the right of $Q^{*}$, which would be the quantity if $A$ is taxed and no shift to $B$ is possible. One of the reasons that a tax or a liability rule may be chosen is officials' lack of knowledge of where the control cost (marginal benefit) curve lies. When in response to a Pigovian tax or liability rule, quantity falls only to $Q_{T}$ rather than all the way to $Q^{*}$ (because of a shift to $B$ ), this may be taken as a sign that control costs are higher than previously thought, i.e. that $C C_{H}$ is really higher such that it intersects the $S\left(T_{A}\right)_{A}$ curve at quantity $Q_{T}$ If so, then the quantity regulation looks deceptively bad. If the optimal point were really at $Q_{T}$, as the liability-rule proponent will now believe, then the amount that the official would have selected ex ante for quantity regulation, $Q_{P}$, looks even more off the mark than it really is: $Q_{T}-Q_{P}>Q^{*}-Q_{P}$. Ex post, the official will take the fall to $Q_{T}$ as evidence that the informational-subset argument worked and very distortive quantity regulation was thereby avoided.

Again, this does not show that property rules and quantity regulation beat liability rules always or even often. What this does suggest is that situations in which indirect quality changes are significant can call for property rules to play some role (alone or in a hybrid scheme). The possibility of indirect quality changes also suggests that where they are important, they will be difficult to ferret out. As in the case of the mandated product enhancement, indirect quality changes in the liability rule arena cause ambiguities in the data that are likely to be used to assess ex post how well the legal rule is working.

\section{IMPLICATIONS AND APPLICATIONS}

Variable quality has additional implications for the analysis of legal rules. In this part, I will focus mainly on these implications for mandates in the buyer-seller context. First, the possibility that price and quantity movements may be motivated by cost-avoiding shifts in quality rather than, or in addition to, shifts in demand makes the data 
more difficult to interpret. Price rises cannot simply be taken as evidence of value placed on the mandate by the marginal consumer without knowing either that adjustments along various quality margins are not possible or that such adjustments can be accounted for econometrically. Neither prospect is all that likely. Unpriced margins abound, precisely because attributes of commodities and services are costly to measure. Further, in many cases a margin of adjustment that corresponds to a costly measurement for transactors will present corresponding or greater measurement costs and information problems for those designing legal rules.

\section{A. Efficiency and Distribution}

First, in both the per-unit and ad valorem cases, the welfare loss and incentive effects of the rules might be different from those anticipated by the lawmaker. The ambiguities in the data make adjustment in these forecasts difficult. The danger will be that a quality change will look like a welfare gain (or non-loss) to the extent there is a price rise (more-than-full, full, or partial), whereas it actually may reflect the legal-rule analog of tax avoidance through quality change. The welfare implications of such quality changes are ambiguous too: the welfare-loss triangle is less than it would be for the corresponding tax, but to this must be added the loss involved in producing a nonoptimal product or service (where optimality is measured by the pre-mandate equilibrium). We may be confronted with a situation that is open to interpretation as market failure with high consumer valuation for the mandate ex post or as an efficient market that is consuming resources to avoid the costs of an unvalued legal mandate. In the most extreme cases, a welfare gain under market failure can be confused with a welfare loss from quality changes. The two situations are quite different, but price rises and quality changes will be ambiguous between these two "readings." Theoretically, additional sophistication in the econometric tools used to interpret this ambiguous data can resolve the ambiguity. As I discuss later, there is little reason to be confident about the ability of these econometric tools to do so. But for now, notice that margins of adjustment may present difficulties for the econometrician for the same reasons that they are left unpriced by unregulated transactors in market equilibrium: attributes are costly to measure. Indeed, the measurement of quality in the course of econometric studies is recognized as at least a difficult and often an unsolvable problem.

Similarly, ambiguities and difficulties arise with respect to the distributional consequences of legal rules. An analysis incorporating variable quality does not change the basic points made by Craswell and others about distribution, but it does have implications for how 
data are treated. ${ }^{139}$ To the extent that quality changes can confuse demand shifts based on the marginal consumer, it will be all the more difficult to tell whether the inframarginal consumer values the product more than, less than, or the same as the marginal consumer. ${ }^{1.0}$ In fact, if one wanted to test by (artificial or natural) experiment the demand by nonmarginal consumers, quality changes will present similar problems for analyzing the behavior of these consumers as was the case for the marginal consumers.

Moreover, if we drop the assumption of homogeneous buyers, we have to face the possibility that the poor and the rich may have different costs of adjustment along the various margins. That is, the shadow price of quality may differ for consumers in different socioeconomic groups. Thus, a quality shift that benefits the marginal consumer by saving more in tax-like cost than it costs in terms of lower overall product value may destroy consumer surplus for inframarginal consumers. The distributional problems facing a lawmaker where consumers of different wealth levels have heterogeneous tastes carries over into the area of variable quality as well.

\section{B. More Complex Cases of Legal Rules}

Legal rules, unlike taxes, can impose costs on unspecified margins. They can impose these costs in a per-unit manner, an ad valorem manner, or somewhere in between. Costs may be imposed in one fashion on one margin but in a different manner on another margin. This section highlights some of the possibilities beyond the product warranty context. Examples are drawn from the law of punitive damages and from mandated health coverage in the employment relation.

\section{Punitive damages.}

Legal rules providing for punitive damages as a remedy may partially impose their costs on an ad valorem basis. In the tax context, Barzel notes that the corporate income tax is fundamentally an ad valorem tax in the sense that it can be partially evaded by substituting

139 Craswell, 43 Stan L Rev at 377-85 (cited in note 1).

140 For a discussion of how monopoly in an aspect of product quality can interfere with the ability of price to convey information about inframarginal consumers? valuation of quality, see A. Michael Spence, Monopoly, quality, and regulation, 6 Bell J of Econ 417, 421, 428-29 (1975). Producers' incentives to provide efficient packages in light of inframarginal consumers' valuations can be affected by economies of scale that prevent satisfaction of diverse preferences. See, for example, Kelvin Lancaster, Variety, Equity, and Efficiency: Product Variety in an Industrial Society 65 (1979); Craswell, 43 Stan L Rev at 373 n 20 (cited in note 1); Avinash K. Dixit and Joseph E. Stiglitz, Monopolistic Competition and Optimum Product Diversity, 67 Am Econ Rev 297 (1977); Michael Spence, Product Differentiation and Welfare, 66 Am Econ Rev (Papers \& Proceedings) 407 (1976). 
towards debt financing and away from equity. ${ }^{141} \mathrm{~A}$ similar point has been made recently by Boyd and Ingberman in the context of punitive damages. ${ }^{1 / 2}$ They note that firms can reduce expected liability by either increasing safety in accordance with the law's purpose or by shifting from equity to debt financing. When firms avoid the cost of the legal rule in the latter fashion, punitive damages have less deterrent effect than expected. That is, where capital investment is endogenous to the legal rule, adjustment may take place along this margin rather than the one envisioned by the lawmaker. In our terms, punitive damages have an ad valorem cost effect: the expected liability is roughly proportionate to the amount of equity capital. If so, the deterrencelessening effect on punitive damages is a case of the expected tendency under legal rules that impose costs on an ad valorem basis; a decrease in quality, here a decrease in equity capital, is expected to result. $^{143}$

2. Employer mandates and behavioral law and economics.

Another complex case of ambiguity arises in the employment context. Sunstein, Jolls, and Thaler cite as support for the endowment effect a study by Jonathan Gruber of the wage and employment effects for female workers after the introduction of mandatory maternity health coverage. ${ }^{1+4}$ The results of the study are consistent with the passing on to the female workers of 100 percent or more of the costs of the mandate, in the form of lower wages. ${ }^{1.5}$ That is, the confidence intervals of most of the regressions that yielded statistically significant results included values "reflecting" full shifting, somewhat less than full shifting, and much more than full shifting. ${ }^{146}$ Sunstein, Jolls, and Thaler point to this as a possible example of the endowment effect: pre-mandate wages reflect lower willingness to pay and post-mandate wages reflect a higher value for the new "endowment." Of course, selection effects could explain this result even without invoking the endowment effect. ${ }^{147}$ As Posner elaborates, women might be attracted to

141 Barzel, $84 \mathrm{~J}$ Pol Econ at $1185 \mathrm{n} 14$ (cited in note 6). Barzel also notes that as a result equity holders will bear more risk and that the corresponding rise in the rate of return will look like the shifting of the tax. In some cases the rise in the rate of return might exceed the tax rate, appearing like a more than 100 percent shift. Id.

142 James Boyd and Daniel E. Ingberman, Do Punitive Damages Promote Deterrence?, 19 Intl Rev L \& Econ 47, 48 (1999).

143 That is, if equity is treated as specified attribute $A$ and debt as unspecified attribute B, the cost on $A$ leads to less of $A$ and more of substitute $B$.

144 Jolls, Sunstein, and Thaler, 50 Stan L Rev at 1505-08 (cited in note 3).

145 Id at 1506; Gruber, 84 Am Econ Rev at 623,630-37 (cited in note 27).

146 Jolls, Sunstein, and Thaler, at 1506 (cited in note 3); Gruber, 84 Am Econ Rev at 638 (cited in note 27).

147 Gruber, 84 Am Econ Rev at 626 n 9 (cited in note 27); Jolls, Sunstein, and Thaler, 50 Stan 
jobs covered by such laws (or attracted to employment over home production), which would compete down wages, and women might be more likely to have children, which would reduce the value of their labor to the employer and lower their wages. ${ }^{148}$

But these possible selection effects are not the only reason that the Gruber results are ambiguous. Variable quality changes may magnify selection effects or, in some cases, even operate independently of them. To simplify for exposition, labor has three attributes: worker identity, hours, and difficulty of task (or skill level). As noted earlier, a legal rule can impose a cost in different ways on different attributes, not all of which need have been specified or even foreseen by the lawmaker. Thus, it is possible for a legal rule to be designed to impose a per-worker flat cost, i.e., on the first attribute, but it may impose an ad valorem cost on the third attribute, skill level. In the case of the Gruber study, if increased pregnancies lead to increased leaves by women, the companies may invest less in their training or entrust fewer long-term projects to them. This would lower'wages. Moreover, this quality-reducing effect can even occur without the selection effects (for increased pregnancies) emphasized by Posner. Consider a mandate (not necessarily like those in the Gruber study) ${ }^{149}$ that included mandatory leave for childbirth. Even if no selection effect existed-no endogenous increased pregnancies - the cost to the employer of this mandate might well be ad valorem: the missed days of more skilled and high-level employees with important firm-specific human capital will impose greater costs than those of less skilled employees entrusted with less complex tasks. If so, the mandate may impose costs partly on an ad valorem basis, which would tend to favor decreased quality by, for example, employing more less-skilled female workers and fewer high-skilled female workers. This would result in lower wages, even in the absence of endowment or selection effects. ${ }^{150}$

The lesson here is not that employer mandates for childbirth are a bad idea. What it does suggest is that, in comparing the various types of mandates and subsidies, endogenous quality along margins like training and task level can be important. ${ }^{1.1}$ Likewise, the costs of

L Rev at 1507 (cited in note 3); Richard A. Posner, Rational Choice, Behavioral Economics, and the Law, 50 Stan L Rev 1551, 1568-70 (1998).

148 Posner, 50 Stan L Rev at 1569 (cited in note 147).

149 The exact contours of the legal rules that Gruber studied are not clear.

150 The Gruber study finds a rise in hours, a drop in employment and little overall effect in labor input quantity. Gruber, $84 \mathrm{Am}$ Econ Rev at 634 (cited in note 27). All this is consistent with an endogenous quality effect if more unskilled labor is required and the mandate imposes a per unit component of costs as well.

151 That there are many margins along which the parties to an employment relation can adjust should be underlined to the extent that workers receive compensating differentials; these are wage differences that reflect the ways in which the fringe benefits of a job differ from the 
measuring quality will factor into the choice among solutions to the quality problem. For example, if the policy for childbirth coverage is important enough, the possibilities are. several. One possibility is to acknowledge the cost in terms of employment but consider that coverage is worth it. Alternatively, the skill level of female workers might have to be specified and monitored, which would be quite difficult. Antidiscrimination law could be used to remedy gender-specific assignment of tasks, which would require measurement of task levels. Or, in the case of mandatory leave, men might be required to take the leave as well. More generally, it is an empirical and policy question whether endogenous quality effects are great enough to matter, and what solution is called for will likewise depend in part on measurement costs. Measurement costs are relevant to the choice of whether and how to intervene in markets.

\section{Measurement Problems}

Endogenous quality is a challenge for those designing legal rules for the same reason that not all attributes are priced in an unregulated market: measurement is costly. In the evaluation of legal rules, empirical studies are correspondingly difficult. In econometric terms, variable quality along multiple margins causes difficult identification problems. Once variable quality is a possibility, identifying the supply curve (or curves) will be difficult because quality is hard to measure. Theoretically, one could use the method of hedonic prices to calculate implicit prices of attributes based on price-quantity observations of multiple goods with different levels of the attribute, ${ }^{1,2}$ but this method,

norm and that help the market clear. See, for example, W. Kip Viscusi, Fatal Tradeoffs: Public and Private Responsibilities for Risk 65 (Oxford 1992); John H. Goddeeris, Compensating Differentials and Self-Selection: An Application to Lawyers, 96 .J Pol Econ 411 (1988); Jonathan Gruber and Brigitte C. Madrian, Health Insurance and Job Mobility: The Effects of Public Policy on JobLock, 48 Indus \& Lab Rel Rev 86 (1994); Sherwin Rosen, The Theory of Equalizing Differences, in Orley Ashenfelter and Richard Layard, eds, 1 Handbook of Labor Economics 641 (NorthHolland 1986). But see Peter Dorman and Paul Hagstrom, Wage Compensation for Dangerous Work Revisited, 52 Indus \& Lab Rel Rev 116 (1998).

152 See, for example, Sherwin Rosen, Hedonic Prices and Implicit Markets: Product Differentiation in Pure Competition, $82 \mathrm{~J}$ Pol Econ 34 (1974) (presenting a model for determining hedonic prices); Timothy J. Bartik, The Estimation of Demand Parameters in Hedonic Price Models, $95 \mathrm{~J}$ Pol Econ 81 (1987) (criticizing the Rosen-Freeman hedonic price model and presenting an alternative); Dennis Epple, Hedonic Prices and Implicit Markets: Estimating Demand and Supply Functions for Differentiated Products, $95 \mathrm{~J}$ Pol Econ 59 (1987). For some of the many attempts to apply the method of hedonic prices to the housing market, see, for example, Werner Z. Hirsch, Effects of Habitability and Anti-Speedy Eviction Laws on Black and Aged Indigent Tenant Groups: An Economic Analysis, 3 Intl Rev L \& Econ 121, 133 n 24 (1983); Werner Z. Hirsch, Habitability Laws and the Welfare of Indigent Tenants, 63 Rev Econ \& Stat 263 (1981); Ann D. Witte, Howard J. Sumka, and Homer Erekson, An Estimate of a Structural Hedonic Price Model of the Housing Market: An Application of Rosen's Theory of Implicit Markets, 47 Econometrica 1151 (1979). 
even where it might apply, requires data on more packages than the quality attributes in question. ${ }^{153}$ In practice this will often be difficult, if not prohibitively so. The problems of identification or the construction of hedonic prices are greater if quality changes are an "evasion technique" for legal rules; it becomes more difficult to identify the supply curve or to specify hedonic prices when quality may respond to changes in legal rules and taxes. The more such margins there are, the more difficult the problem is.

Likewise, endogenous quality changes, when they occur, are caused by the legal rule and are thus expected to occur at the same time as the other price and quantity effects of the rule. There is no reason to expect a difference in timing to allow one to tell the difference between cost-evading quality changes and other demand-shifting factors stemming from the legal rule.

The issues here may be illustrated using one of the best-studied areas of the effects of legal rules, housing codes. Here quality is key, in an obvious way: the code designers are worried about "low-quality" housing. Thus, price alone is not enough for the evaluation of the efficiency and distributional impact of such rules. However, in the many studies that have been done, quality has been addressed less than convincingly. The most promising approach has been that of implicit or hedonic prices just mentioned, but many problems remain, including biases from omitted variables. ${ }^{134}$ Quality dimensions that are difficult to measure can lead to such biases, and quality is directly related to the question of how many dimensions should be used to measure market segmentation. ${ }^{1.5}$

In general, studies evaluating legal rules tend to look at quality dimensions foreseen by the lawmakers. Thus, for housing, such studies will include, at most, variables for aspects such as completeness of

153 Leffler, 72 Am Econ Rev at 965-66 (cited in note 6).

154 See, for example, David Dale-Johnson, An Alternative Approach to Housing Market Segmentation Using Hedonic Price Data, $11 \mathrm{~J}$ Urban Econ 311 (1982); Robert Halvorsen and Henry O. Pollakowski, Choice of Functional Form for Hedonic Price Equations, $10 \mathrm{~J}$ Urban Econ 37 (1981) (reporting on a study of 5727 single-family owner-occupied homes in the San Francisco Bay Area involving seven variables); Peter Linneman, Some Empirical Results on the Nature of the Hedonic Price Function for the Urban Housing Market, 8 J Urban Econ 47 (1980) (analyzing 1973 American Housing Survey data involving thirty variables but recognizing that some important variables were not available); Michael P. Murray, Hedonic Prices and Composite Commodities, 5 J Urban Econ 188 (1978) (defending traditional housing service model while recognizing the limits of the hedonic price approach); Raymond B. Palmquist, Measuring Environmental Effects on Property Values without Hedonic Regressions, 11 J Urban Econ 333 (1982). See also, for example, James N. Brown and Harvey S. Rosen, On the Estimation of Structural Hedonic Price Models, 50 Econometrica 765,767 (1982) (arguing that 'marginal 'prices' constructed only from quantities do not in themselves add any information to that already provided by observations on quantities" and that the additional information must come from prior restrictions on functional form).

155 See, for example, Dale-Johnson, $11 \mathrm{~J}$ Urban Econ at 313 (cited in note 154). 
plumbing, exposed wires, etc., ${ }^{156}$ but not aspects like length of lease, the extent to which late rental payments are tolerated, sound buffering, etc. But other quality dimensions seemingly unrelated to the legal rule in question may be used to evade the cost of the legal rule, along the lines discussed earlier. Thus, to take a purely hypothetical example, consider a housing code that imposes some costs that do not vary much if at all with the length of the lease. This could happen in several ways. First, a code could make landlords responsible for ensuring no floor tiles are cracked or missing (or any other similar damage). Suppose tenants would be responsible for tiles they themselves damaged during the term of the lease and that such damage tends to go unreported during the term. Renting to irresponsible tenants whose security deposits may not cover full damage would under such a code entail a roughly per-unit cost for each lease: the fix-up costs would be a per-unit cost regardless of the length of the lease. Second, the code might regulate and impose costs on the process of turnover itself, for example by giving a right to damages to new tenants whose apartments are not ready on time. Third, the code might impose costs on a per-lease basis by, for example, making it the landlord's duty to ensure that certain higher standards are met at the beginning of a lease. This could also occur where enforcement of a standard that theoretically applied at all times tended to occur at the beginning of leases.

Such per-unit-here per-lease-costs might be partially evaded by lengthening the period of the lease, somewhat like the longerlasting light bulbs or longer cigarettes enabled transactors to partially evade a per-unit excise tax. As noted earlier, tenants might value the uncracked tiles somewhat, so the analogy to the excise tax should not be pushed too far. But, to the extent that the repair is valued by the marginal tenant at less than its marginal cost, the tax-like excess cost can lead to quality changes-here a lengthening of lease terms - that avoids some of this excess cost.

Note too that such quality effects, to the extent that they occur, have implications for efficiency and distribution. The legal rule will cause a loss from more costly production, but a lesser deadweight loss triangle, and will have less of its intended impact. Also, not only will tenants value the improvement in quality envisioned by the lawmaker differently, but different tenants may place different value or bear different costs from the cost-evading quality improvement. In the example, some tenants may find longer leases more inconvenient than does the marginal tenant.

The result of these measurement difficulties is often an excessive focus on price alone. To return to the area of excise taxes, one would

156 See, for example, Hirsch, 3 Intl Rev L \& Econ at $134 \mathrm{nn}$ 25-28 (cited in note 152). 
think that sales of cigarettes would not be overly difficult to study; certainly cigarettes are much less complex commodities than housing. But here empirical support for the theory of taxation based on variable quality had to await an approach that went beyond crude assumptions of price response. Many studies in the last 20 years purporting to refute Barzel's theory of taxation relied on price alone. Because of limited data on even such a seemingly simple commodity, authors measured product quality indirectly using data on the price of packs of cigarettes. ${ }^{157}$ But the introduction of generic cigarettes allowed a natural experiment, and it appears that indeed per-unit taxes lead to an increase in cigarette quality and that ad valorem taxes have a different effect. s. $^{\text {1ss }}$

Likewise, in evaluations of the possible role played by framing effects, price has been the primary focus. If framing is to explain price increases, we should expect quantity increases as well, but flat or slightly declining quantity is taken as consistent with framing. ${ }^{159}$ If so, quantity is not going to distinguish between competing interpretations of the data.

This focus on price is understandable, if regrettable. First, in a competitive market there will be little variation in price, making price much easier to measure than total quantity sold (which requires tallying up units across a market). Further, as we have seen, the quantity effects expected may not be large; if so, the quantity effects that one would expect from cost-evasion through variable quality might differ so little from the quantity effects expected where consumers value the legal mandate that the difference is drowned out in statistical noise. This will be all the easier the closer the case comes to the double ambiguity - of both price and quantity - set out above in Part IV.A.

A small quantity effect is especially to be expected in the area of taxes and legal rules because proposals have typically focused on situations where "supply" is-or is thought to be-relatively inelastic. It is thought that where supply is relatively inelastic, decisionmaking will be least affected and distortions correspondingly smaller. ${ }^{160}$ Not

157 See Sobel and Garrett, $105 \mathrm{~J}$ Pol Econ at 881-82 (cited in note 7).

158 Id at 881-83.

159 Jolls, Sunstein, and Thaler, 50 Stan L Rev at 1506 (cited in note 3).

160 This is true both of the Ramsey rule in the optimal taxation literature, Frank P. Ramsey, A Contribution to the Theory of Taxation, 37 Econ J 47 (1927) (proposing inverse-elasticities rule), and of proposals for legal rules. For example, Ackerman's argument for the potential desirability of housing codes rested in part on the relatively inelastic supply of housing. Bruce Ackerman, Regulating Slum Housing Markets On Behalf of the Poor: Of Housing Codes, Housing Subsidies and Income Redistribution Policy, 80 Yale L J 1093, 1102-03, 1117 (1971) (setting out initial analysis including inelastic supply and noting that more government provision of lowincome housing will be required the more that reality deviates from this assumption); Bruce Ackerman, More on Slum Housing and Redistribution Policy: A Reply to Professor Komesar, 82 Yale L J 1194 (1973). But see, for example, Neil K. Komesar, Return to Slumville: A Critique of 
only is an exclusive focus on price and "passing on" of costs (observed in judicial opinions) inappropriate because demand may shift, ${ }^{161}$ the focus on price can obscure the effects of quality adjustment. Thus, the class of econometric problems posed by legal rules (and taxes) is not randomly chosen. Inelastic supply will lead the quantity effects to be small regardless of their source and the price effects to be relatively larger. Thus, although theoretically "quantity" effects could sometimes help decide whether we are dealing with framing effects and arguably increased efficiency or with evasion and a welfare loss, in practice they do not.

And, as we have seen, a focus on price alone is subject to ambiguities. Is a price rise the effect of a per-unit cost along some margin or the result of consumer valuation (for framing or other reasons)? Is a price drop the result of an ad valorem cost or lack of consumer valuation? And most disturbingly of all, what combination of these four possibilities lies behind the overall rise or fall that we actually see?

The key is what margins to look for and the cost of measuring them. Studies evaluating the "quality" effects of legal rules - to the extent that they exist-tend to look first to price effects and then to crude measures of the quality margins most related to what the lawmakers had in mind. Of course, these tend to be ones that are easier to measure. The problem is even greater for legal rules than it is for taxes because legal rules can impose costs on unspecified margins.

\section{CONCLUSION}

Measurement costs are what lead to attributes being unpriced, untaxed, and unregulated. Although transactors' and lawmakers' costs may not be the same, often they will be similar enough for the set of margins that is left unspecified by market price, by tax statute, and by legal rule to be similar. Even the question of how the world is carved up into "products" and "activities" is partly a function of measurement costs. It is doubtful that the analyst will often have the information at a worthwhile cost when the market does not.

the Ackerman Analysis of Housing Code Enforcement and the Poor, 82 Yale L J 1175 (1973); Posner, Economic Analysis of Law at 514-18 (cited in note 83) (arguing that rent supplements are superior to housing codes in improving the stock of housing for the poor). See also Richard S. Markovits, The Distributive Impact, Allocative Efficiency, and Overall Desirability of Ideal Housing Codes: Some Theoretical Clarifications, 89 Harv L Rev 1815, 1818-27 (1976).

161 Craswell points out that Judge J. Skelly Wright, in using (and citing) Ackerman's article, took the extent to which costs could not be passed on as an index of tenant net benefit. Craswell, 43 Stan L Rev at 383 \& n 35 (cited in note 1), citing Robinson v Diamond Housing Corp, 463 F2d 853,860 (DC Cir 1972). 
As we have seen, the analogy between legal rules and taxes can provide additional insights, once we allow for variable quality. Legal mandates are unlike taxes in sometimes providing buyers with nonzero value as well as cost. But to the extent that the mandate is not cost justified, it can lead to cost-evading quality adjustments. The set of possible adjustments to legal rules properly includes those in response to the corresponding tax. And the adjustments themselves lead to ambiguities, for example where quantity and (especially) price changes could reflect an outward shift in demand or a cost-evading increase in quality.

Similarly, where measurement of the possible components of an externality-generating activity are differentially costly to measure, simple informational-subset arguments for Pigovian taxes and liability rules cannot be maintained without qualification. Rather, the question is an empirical one, and the data used ex post to evaluate the pricing of externalities can be subject to ambiguities from indirect quality effects.

Generally, adjustment to taxes and legal rules can occur along margins that are unspecified and which allow for cost evasion. Often the costs of measurement are what cause margins to be unpriced by the market. The history of empirical study of quality changes in response to excise taxes illustrates only some of the problems involved. In the case of legal rules aimed at product enhancement or externalities, quality adjustments along such margins will cause the data used for ex post evaluation to be at least as, if not more, ambiguous than those used to evaluate excise taxes. Correspondingly, endogenizing quality is potentially important in evaluating the desirability of a legal rule.

Most basically, we need to know if a price rise corresponds to an adjustment for per-unit costs on the one hand or reflects consumer or social value on the other. Similarly, a price drop will raise the possibility of a cost-evading drop in quality or a drop in consumer valuation. Most importantly, we need to distinguish between these four possibilities-and along a number of margins. The possibilities become very numerous and hard to disentangle. Moreover, induced quality changes have implications both for efficiency and for distribution. Particularly where a legal rule is designed to benefit a socioeconomic group, it is necessary to have some idea about whether the quality change that responds to the desires of the marginal consumer has the same or different impact on inframarginal consumers. 


\section{APPENDIX}

In this appendix, I present a more formal version of the arguments in Part II of the text and extend Barzel's model of excise taxation to the complex case of a mandated product enhancement.

\section{A. Per-Unit Legal Rules}

In the pre-mandate equilibrium, for all attributes $i=1, \ldots, n$, the marginal contribution of the attribute to the value and to the cost of the commodity (denoted $M V C_{i}$ and $M C C_{i}$, respectively) are equal $\left(M V C_{i}=M C C_{i}\right)$. I assume that marginal cost with respect to quantity is positive and increasing and marginal benefit is positive and decreasing over the relevant range. Normalizing the pre-tax level of each attribute to one unit per unit of the commodity, and assuming additive separability for the contributions of the attributes, we have

(1) $M C C=\sum_{i=1}^{n} M C C_{i}$

and

(2) $M V C=\sum_{i=1}^{n} M V C_{i}$.

The warranty will impose a marginal cost $(M C W)$ consisting of components that vary with the level of the other attributes $\left(M C W_{i}\right)$ and a fixed cost once the product is chosen $\left(M C W_{o}\right)$, that is

(3) $M C W=\sum_{i=0}^{n} M C W_{i}$,

and correspondingly on the marginal value side

(4) $M V W=\sum_{i=0}^{n} M V W_{i}$.

Now, with the imposition of the warranty, the new equilibrium will be characterized by the equality of the sum of the marginal costs of all the attributes (including the marginal cost of the warranty attribute) on the one hand and the sum of the marginal values of the attributes on the other: 
(5) $\sum_{i=1}^{n} M C C_{i}^{W}+\sum_{i=1}^{n} M C W_{i}+M C W_{0}=P^{W}=$

$$
\sum_{i=1}^{n} M V C_{i}^{W}+\sum_{i=1}^{n} M V W_{i}+M V W_{0}
$$

Note that for convenience I am writing $M C W$ and $M V W$ as sums of their variable and fixed components.

As noted in the text, the situation here differs from that of a tax in that (i) the effect of the warranty appears on both sides of equation (5) because the legal rule can confer benefits (reflected in the two marginal value terms on the right of the equation) and (ii) the levels of the attributes of the pre-mandate commodity can affect the cost and benefit of the warranty attribute, as reflected in the second terms on each side of equation (5). As noted in the text, I focus on modeling the interaction of the attributes with the warranty and abstract away from similar effects among the non-warranty attributes. ${ }^{162}$

We can simplify by reducing the specified and unspecified attributes to composite attributes $A$ and $B$, respectively. ${ }^{163}$ Equation (5) then decomposes into the following:

$$
\begin{aligned}
& M C C_{A}^{W}+M C W_{A}+M C C_{B}^{W}+M C W_{B}+M C W_{0}=P^{W}= \\
& M V C_{A}^{W}+M V W_{A}+M V C_{B}^{W}+M V W_{B}+M V W_{0} .
\end{aligned}
$$

At this point, results depend on the relative sizes of the terms in this equation. Most significantly, the issue is whether the warranty itself is less than, more than, or exactly cost justified.

1. Non-cost-justified warranty.

In this first case, the marginal value of the warranty is less than its marginal cost $(M V W<M C W)$. Here variable quality can lead to ambiguity between a cost-evading quality shift and a shift outward in demand.

Whenever the warranty is not cost-justified, it does act like a tax in the sense that, under the assumptions adopted here, it will lead to a decrease in the quantity of the commodity as a whole, which in turn means that we move downward along the marginal cost curves of each of the attributes:

162 See note 56 and accompanying text.

163 For the reasons for exploring an additive transformation of the supply schedules for the attributes, see notes 53 and 57 and accompanying text. 
(7) $M C C_{i}^{W}<M C C_{i}=M V C_{i}<M V C_{i}^{W}$ for all $i$.

Now we consider some possible subcases.

a) The marginal cost and value of the warranty may be unaffected by the level of the attributes, both specified and unspecified. That is, altering the level of the product's attributes does not affect the cost and value of the warranty: $M C W_{A}=M C W_{B}=M V W_{A}=M V W_{B}=0$. The "direct" effect of quality on the cost and value of the warranty is nonexistent. In the toaster example, this is where improving the wiring would cost more than it contributes to reducing the cost of the warranty.

If so, then the only quality effect is indirect, and we have a legal rule that acts very much like the per-unit excise tax on light bulbs. In the case of the legal rule, the "tax" is the amount by which the marginal cost of the warranty exceeds its marginal value. What is analogous here to the per-unit tax is the amount by which the marginal cost of the warranty exceeds its marginal value $(M C W-M V W)$. Given equations (6) and (7) above, along with the assumption of $M V W<$ $M C W$ for this scenario, we have:

$$
M C C_{A}^{W}+M C W_{0}>M V C_{A}^{W}+M V W_{0}
$$

and

(9) $M C C_{B}^{W}<M V C_{B}^{W}$.

On the assumption of this scenario $\left(M C W_{A}=M C W_{B}=M V W_{A}=\right.$ $M V W_{B}=0$ ), altering the levels of the other attributes of the product does not affect the value of the warranty, and so the only reason to change those levels is for the tax-avoiding reasons discussed in connection with the light-bulb case. ${ }^{16}$

For the specified attribute set $(A)$, the warranty effectively sets a minimum level and there is no incentive to increase it (see (8)). Adjustment then takes two forms: a reduction in quantity and an increase in $B$ relative to $A$, as discussed earlier. For example, unspecified durability $(B)$ can be increased relative to the specified attributes that are included in the definition of "toaster" $(A)$. In addition, for the unspecified $(B)$ attributes, the lower quantity has caused a move down the attribute's marginal cost curve $\left(M C C_{B}\right)$ and up its marginal benefit curve $\left(M V C_{B}\right)$. The amount of $B$ will be increased until the marginal cost of $B$ equals its marginal value until an equilibrium is restored (that is, until the inequality in (9) turns into an equality). Because adjustment takes the form of both a reduction in quantity and an in- 
crease in quality (the relative level of $B$ increases), the reduction in quantity need not be pursued as far as it would under rigid quality.

Thus, we would expect a tendency toward somewhat lower "quantity" but higher levels of the unspecified attribute and hence a higher price than expected in the rigid-quality framework. ${ }^{165}$ Thus, attributes, like durability, will be increased only insofar as they allow a substitution against the tax. Again, where the legal rule has no value to the consumer, the cost of the mandate does act like a tax, but with variable quality this can lead to a price increase. Price will be higher than expected on rigid quantity and can even exceed the pre-mandate equilibrium price plus the cost of the warranty.

b) The contribution of the level of the unspecified attributes to the marginal cost of the warranty is less than the contribution of the level of those attributes to the marginal value of the warranty. That is, $M C W_{B}<$ $M V W_{B}$. Here, there is an incentive to raise the level of the unspecified attributes in order to make the warranty less costly or more valuable, reinforcing the tendency toward higher quality just discussed under subcase (a). This extra motive to increase quality is familiar from products liability and is what I have labeled the "direct effect" on quality. For example, we might expect that, in some cases, it will be cost effective to increase product safety in response to a warranty in order to make the warranty less costly. Alternatively, to the extent that consumers value the extra warranty coverage enough to exceed the cost of the additional coverage, it is possible for the increase in quality to enhance the value of the warranty. Particularly where there is no choice but to have the warranty, the marginal consumer can value the warranty in the presence of high quality more than with low quality, even though the warranty-plus-high-quality package is valued less than the no-warranty-low-quality package. In such a case, the premandate equilibrium will be no warranty and low quality and the post-mandate equilibrium will be high quality plus warranty. This is the case in which the net positive contribution that the level of $B$ makes to warranty value reinforces the cost-evading tendency to higher quality. One example is increased safety in response to tort liability.

c) The contribution of the level of the specified attributes to the marginal cost of the warranty is less than the contribution of the level of those attributes to the marginal value of the warranty. That is, $M C W_{A}<$ $M V W_{A}$. Here, the specified attributes are net contributors to warranty value and exert a pressure towards higher quality. Note that this can-

165 As for legal rules, perhaps in some ways a mandated pollution control device for automobiles comes closest to this most tax-like case. Altering the levels of other attributes of the car does not increase or decrease the net cost of the device (its tax-like aspect). 
not happen in the case of a tax, which does not normally have value to the consumer. The most interesting scenario is one in which this quality-increasing effect outweighs the unattractiveness of the specified attributes from the constraint of the legal rule. Given equation (8) above, this will happen when

$$
M V W_{A}-M C W_{A}>M C C_{A}^{W}+M C W_{0}-M V C_{A}^{W}-M V W_{0}
$$

As a result, we get

$$
M V C_{A}^{W}+M V W_{A}+M V W_{0}>M C C_{A}^{W}+M C W_{A}+M C W_{0} .
$$

Increasing the level of the specified attributes might make the warranty more valuable, but for this effect to matter, it has to call for a level of $A$ that clears the floor established by the rule.

In a way, this is more likely than in the previous subcase (in which increasing the level of unspecified attributes made the warranty more valuable) because officials might well have contemplated that these attributes needed adjustment. But, as the literature on cheapest-costavoider under strict liability argues, one of the advantages to strict liability is that it allows the actor with the most information to adjust along the appropriate margins. ${ }^{166}$ These margins need not even have been foreseen by the lawmaker for the liability rule to work. Thus, this case and the previous case are similar.

In the next subcases, (d) through (g), the marginal cost of the warranty exceeds its marginal benefit as before, but in the case of an attribute (unspecified or specified), we now compare the following: the excess of the attribute's contribution to the marginal value of the product over its contribution to the marginal cost on the one hand and, on the other hand, the "tax-like" excess of the attribute's net contribution to the marginal cost of the warranty. That is, in deciding the level of an attribute that is a net contributor of value to the product proper and a net detractor of value through its interaction with the warranty, we must compare the sizes of the two effects to decide the direction of any quality change.

d) The unspecified attribute's net contribution of value to the product exceeds its net contribution to the warranty's cost. That is,

(12) $M V C_{B}-M C C_{B}>M C W_{B}-M V W_{B}$.

This case is not unlike the one in (a) above (where the attribute did not contribute to warranty benefit or cost; that is, where $M C W_{B}=$ $M V W_{B}=0$ ), with the exception that the expected quality increase 
from adding more $B$ will not proceed as far as in that earlier case. This is because the level of $B$ will be increased only until (12) becomes an equality. This will happen at a point earlier than in (9) of case (a) above, because increasing the attribute not only increases the marginal value of the product proper but also increases the marginal cost of the warranty. That is, when, as here, increasing the level of $B$ both increases the value of the product but also imposes a cost through the warranty, the latter effect will cause the increase in $B$ to stop short of the point at which the costs and benefits in the product proper would dictate.

e) The unspecified attribute's net contribution of value to the product is smaller than its net contribution to the warranty's cost. That is,

$$
\text { (13) } M V C_{B}-M C C_{B}<M C W_{B}-M V W_{B}
$$

Here, in a reversal of the previous scenario, the negative warranty effect dominates the positive product-proper effect. Correspondingly, we expect a decrease in unspecified attributes, and a lowering of quality. This is interesting because it cannot happen in the case of a specific excise tax. Whereas, in the case of a per-unit tax under the assumptions we are entertaining, we would never expect a decrease in unspecified attributes, this can happen in the case of a legal rule. We expect a quality decrease in the case where raising the amount of the unspecified attributes is more costly through its effect on the warranty cost than it is beneficial as part of the product proper.

$f), g$ ) A specified attribute that is a net detractor of value from the warranty can contribute $(f)$ more or $(g)$ less to the marginal value of the product than it detracts from the marginal value of the warranty. Here we are considering the relationship of the net contribution of the specified attribute $(A)$ to the value of the product and to the warranty under the assumption that the net contribution of value to the warranty is negative. However, recall that, by (8) above, the level of $A$ is effectively constrained. As long as the legal rule does not allow the level of $A$ to fall and there is no incentive to raise it (as in these subcases), then the level of the specified attributes is not expected to change. ${ }^{167}$

\section{Cost-justified warranty.}

Here the marginal value of the warranty equals or exceeds the marginal cost $(M V W \geq M C W)$. In these cases, demand shifts outward,

167 That is, in such cases, the legal rule and the excise tax behave similarly. See Barzel, $84 \mathrm{~J}$ Pol Econ at 1181 (cited in note 6). 
but quality changes can occur if the (overall) cost-justified mandate imposes costs on unspecified margins.

\section{B. Ad Valorem Legal Rules}

The ad valorem legal rule imposes costs in proportion to the amount of all attributes that happen to be in the "product," giving rise to an incentive to hive off attributes to evade the tax. With costs at rate $c^{w}$ and benefits at rate $v^{w}$, for the product as a whole we have:

(14) $\left(1+c^{w}\right) \sum_{i=1}^{n} M C C_{i}^{W}=P^{W}=\left(1+v^{w}\right) \sum_{i=1}^{n} M V C_{i}^{W}$

This can be expanded in several ways. First, we can break up the $n$ attributes into the constrained $(A)$ and unconstrained $(B)$ sets, as above in the per-unit case. Further, unlike with a tax, the legal rule can impose different costs for different attributes. Also, although I will not pursue this in detail, the "tax rate" and "benefit rate" that an ad valorem legal rule applies to an attribute might well depend on the level of that attribute: the cost and benefit rates are functions of the attribute level.

$$
\begin{aligned}
&\left(1+c^{w}(A)\right) M C C_{A}^{W}+\left(1+c^{w}(B)\right) M C C_{B}^{W}=P^{W}= \\
&\left(1+v^{w}(A)\right) M V C_{A}^{w}+\left(1+v^{w}(B)\right) M V C_{B}^{w}
\end{aligned}
$$

As with the ad valorem tax, the legal rule that imposes costs on an ad valorem basis makes lower quality attractive; reducing levels of $B$ allows some of the cost to be avoided because $B$ is only exposed to the cost of the rule as part of the product. When value might exceed the cost $\left(v^{w}>c^{w}\right)$, demand shifts outwards, but when the cost exceeds the value $\left(c^{w}>v^{w}\right)$, then the rule operates as a tax at the rate $\left(c^{w}-v^{w}\right)$. We expect that $B$ will be decreased to avoid the cost of the rule as long as any inconvenience of doing so is outweighed by the tax-like cost saved. If the pre-mandate benefit from selling $B$ as part of the package (as opposed to separately) is less than

$$
\left(c^{w}-v^{w}\right) M C C_{B}^{W}
$$

then $B$ may be dropped from the "product" completely. Thus, the legal rule that imposes costs on an ad valorem basis tends to lead to lower quality and lower price than expected on rigid quality. 


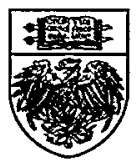

